متطلبات حائزي المزارع السمكية في محافظة الفيوم

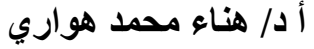

غادة عثمان ميزار ونيس

قسم الاقتصاد الزر اعي ـ كلية الزر اعة - جامعة الفيوم

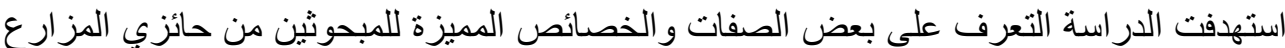

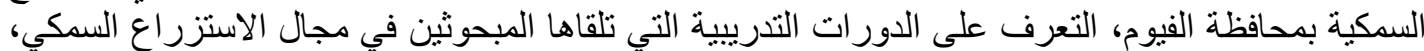

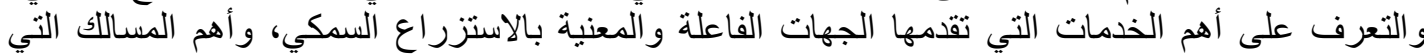

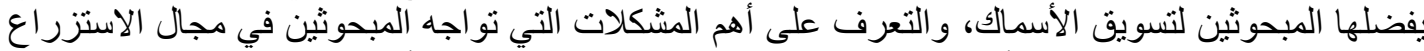

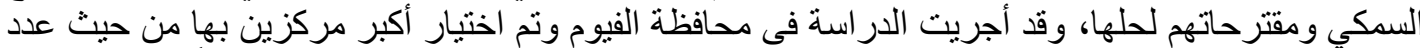

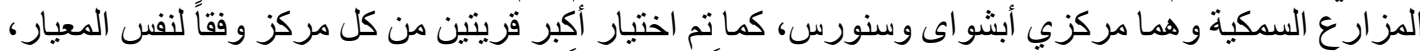

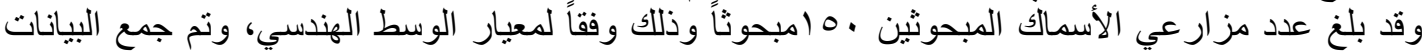
بالمقابلة الشخصية باستخدام استمارة استبيان.

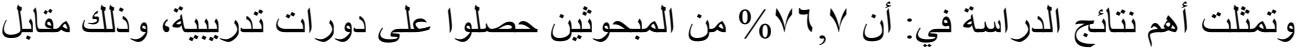

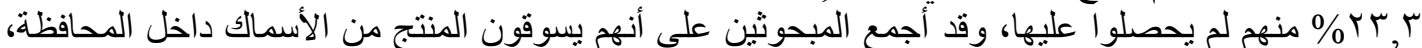

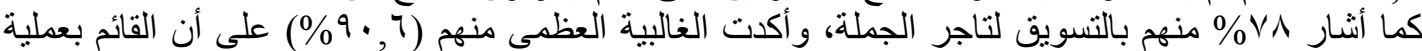

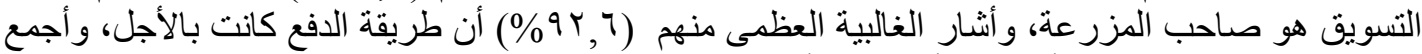

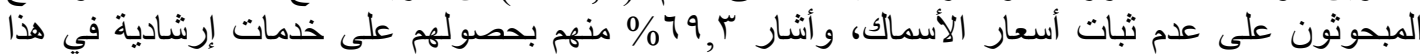
المجال، وكانت أهم الجهات الفاعلة هي: القطاع الخاص الثاص (شركات الأعلاف)، و الهيئة العامة لتنمية الثنروة

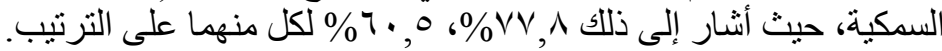

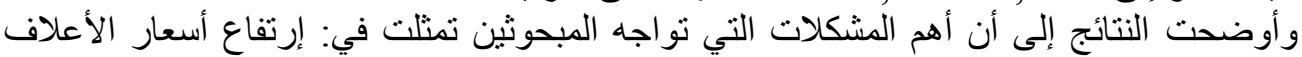

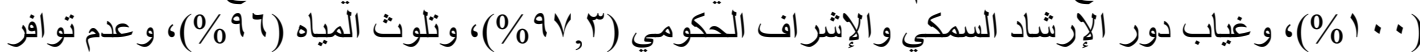

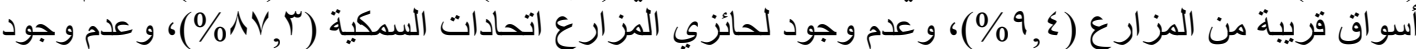

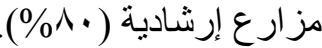

مقدمة ومشكلة الاراسة الاسة

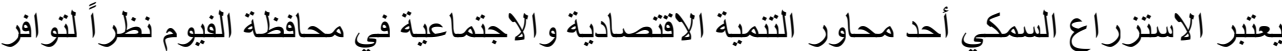

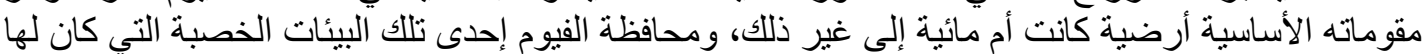

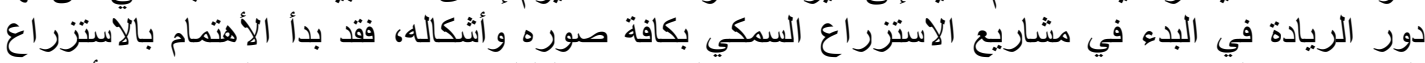

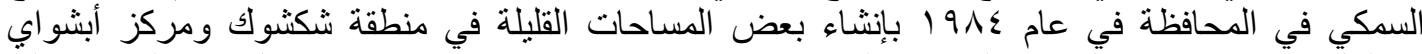

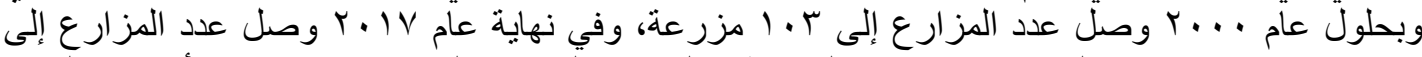

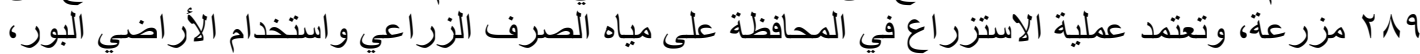

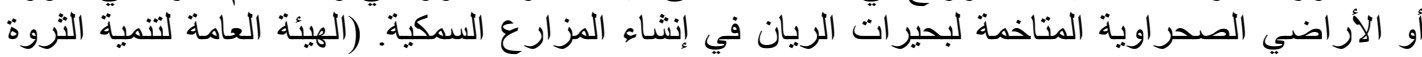

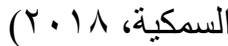

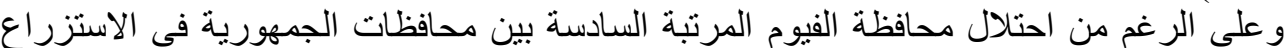

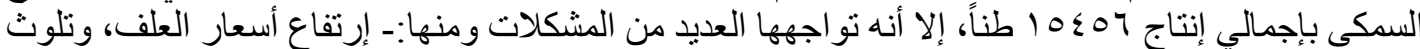

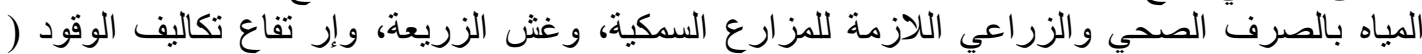

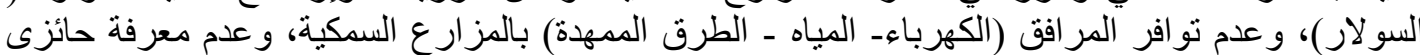

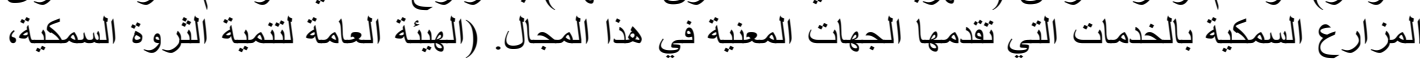

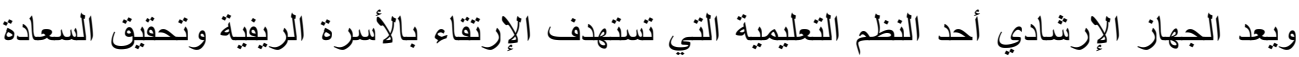

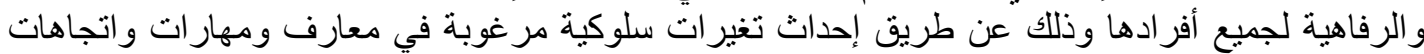
جمهور الريفيين، وتؤكد مختلف المؤلفات الإرشادية على أهمية حاجات المسترشدين كمنطلق أساسي في في

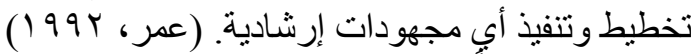

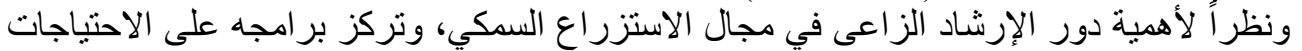

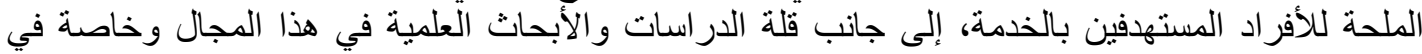

Fayoum J. Agric. Res. \& Dev., Vol. 34, No.2 July, 2020 


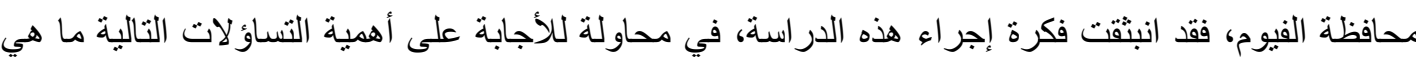

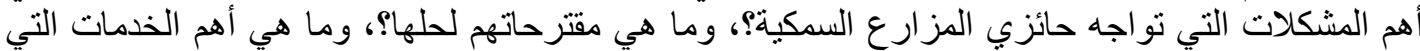
يقدمها الجهاز الإرشادي الزراعي في هذا المجال؟، وما هي المسالك التي يفضلها الميات المبحوثين لتسويق الأسماك؟.

ا ـ التعرف على بعض الصفات و الخصائص المميزة للمبحوثين من حائزي المز التهارع السمكية بمحافظة الفيوم.

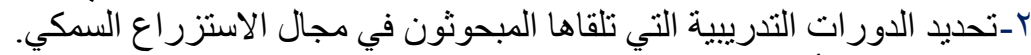

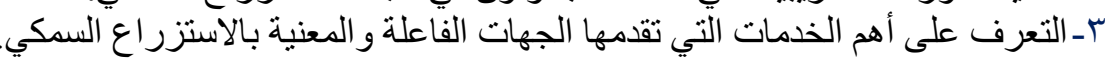

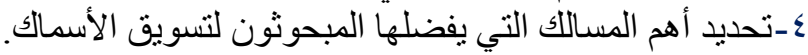

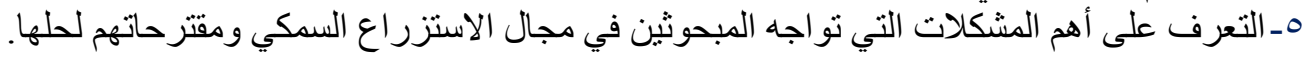

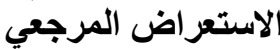

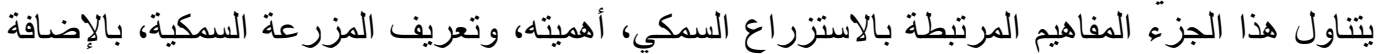

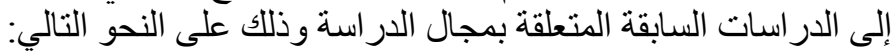

ـ مفهوم الاستزراع السمكي وأهميته

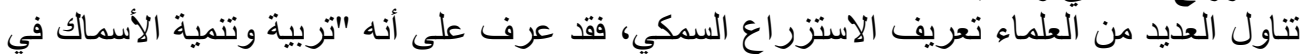

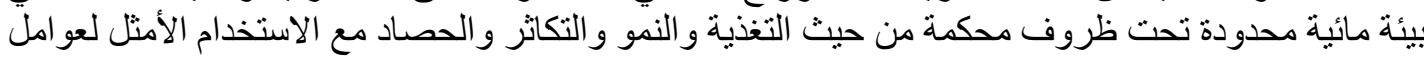

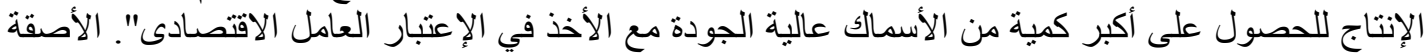

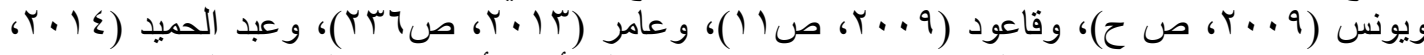

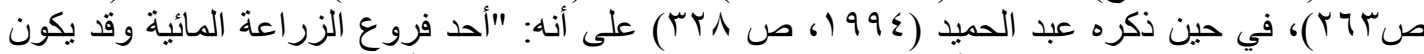

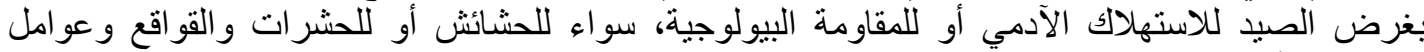

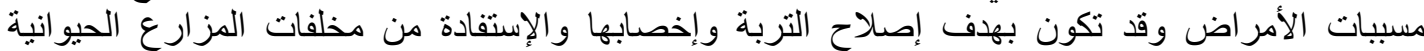

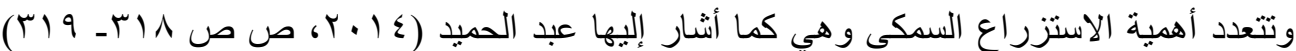

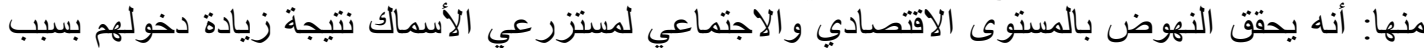

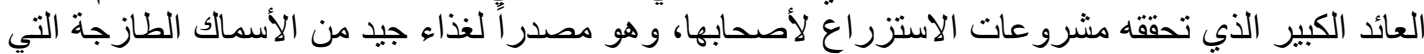

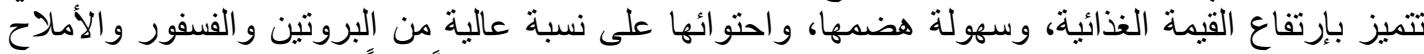

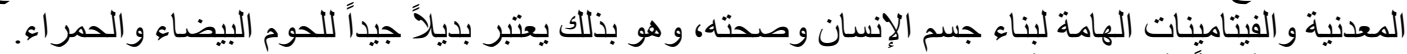

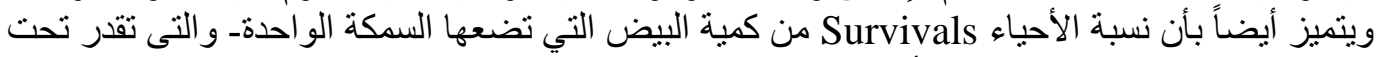

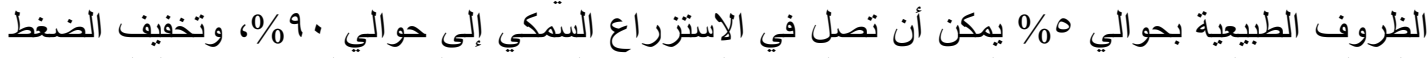

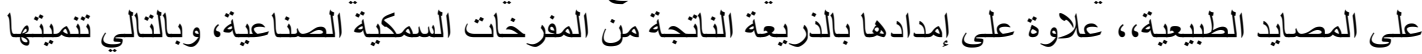

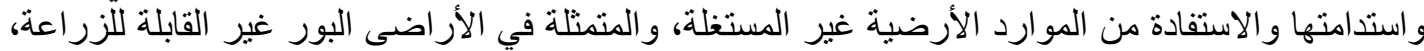

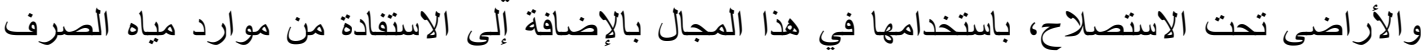

وتعرف المزرعة السمكية على أنها: "وحدات لتربية الأسماك ورعايتها خلال فترة زمنية معينة،

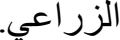

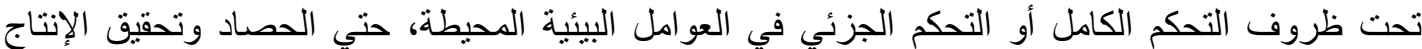

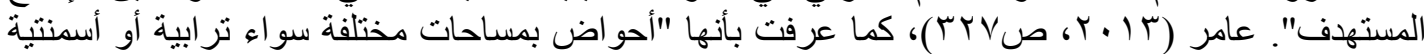

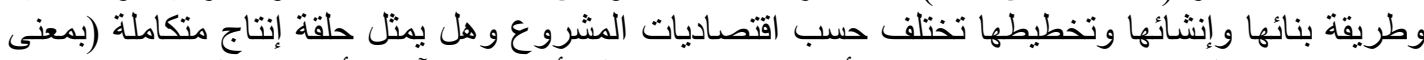

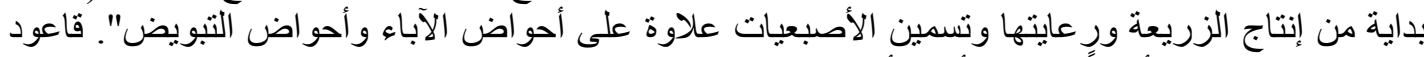

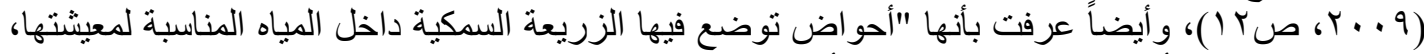

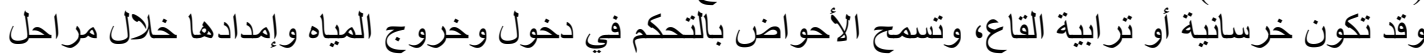

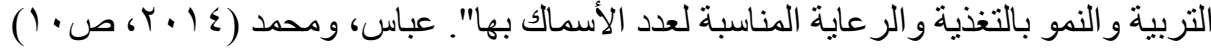

أهتمت العديد من الدراسات التي إتيح الأطلاع عليها بالتعرف على أهم المشكلات التي تواجه

الاراسات السابقة

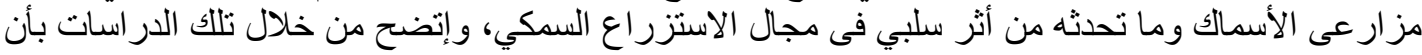

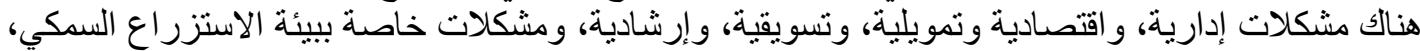
ومشكلات فنية، و التي يمكن عرضهات والئها فيما يلي:

Fayoum J. Agric. Res. \& Dev., Vol. 34, No.2 July, 2020 
أـ المشكلات الإدارية: تتمثل في فرض الضرائب على المزارع السمكية وإرتفاع تقدير اتها، وكثرة مشاكل

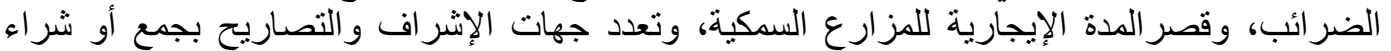

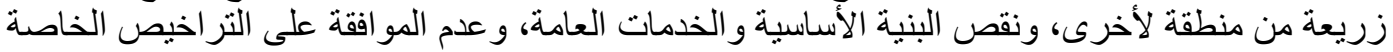

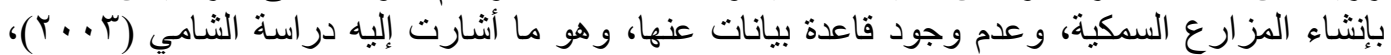

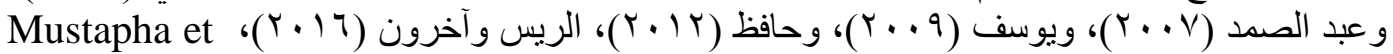

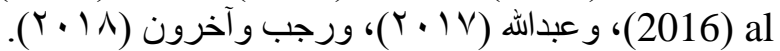

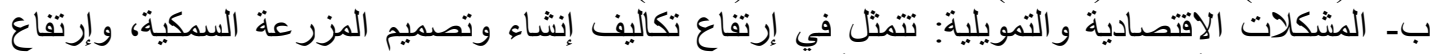

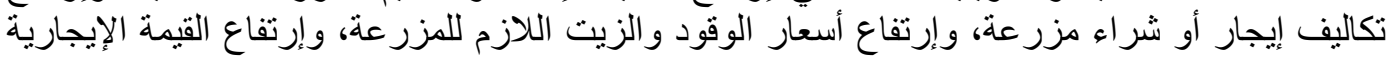

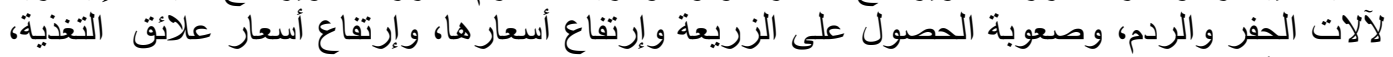

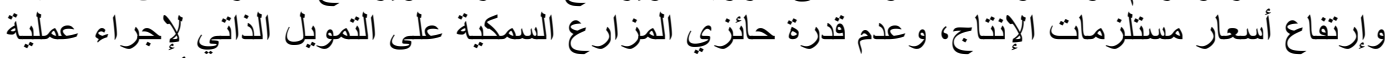

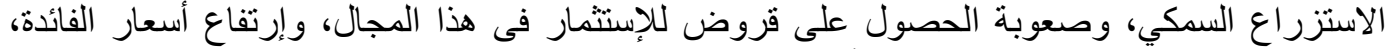

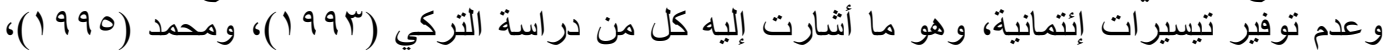

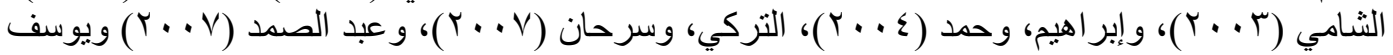

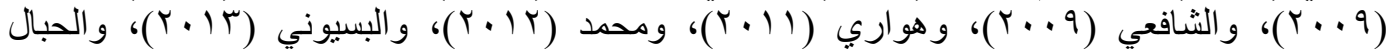

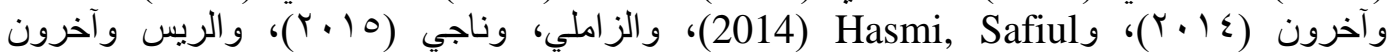

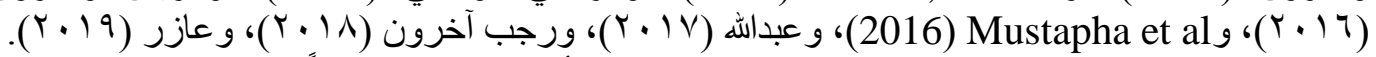

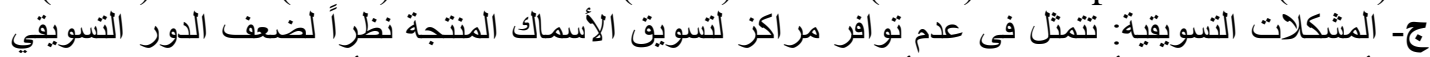

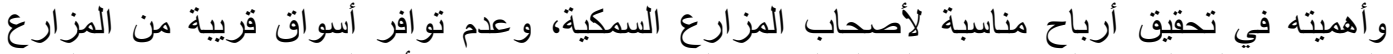

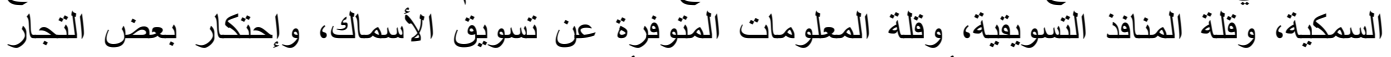

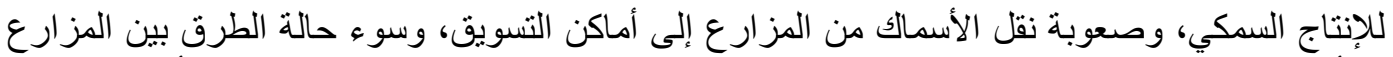

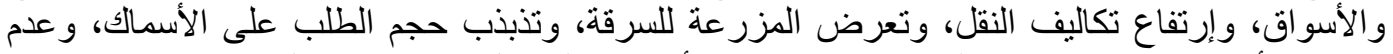

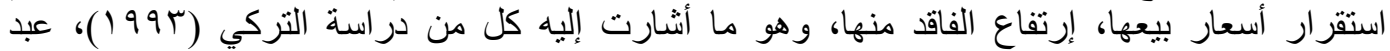

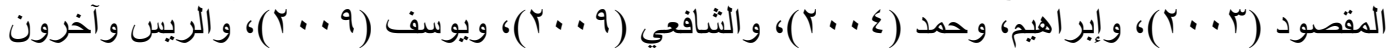

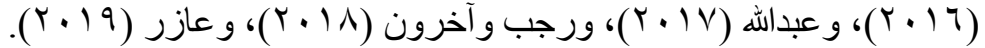

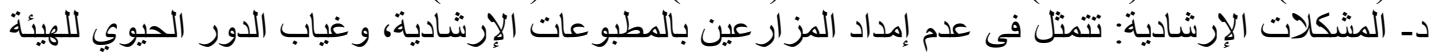

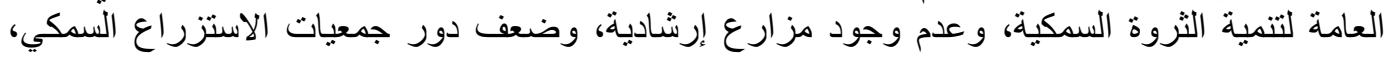

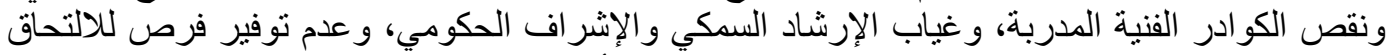

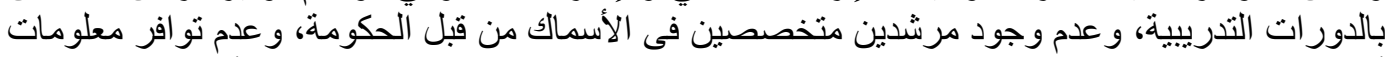

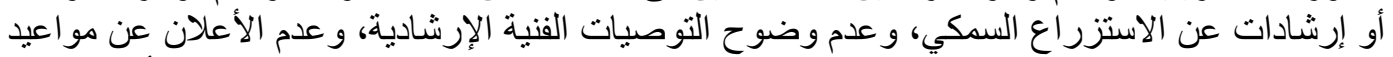

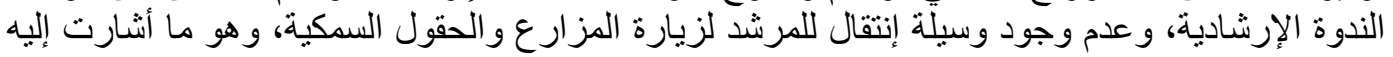

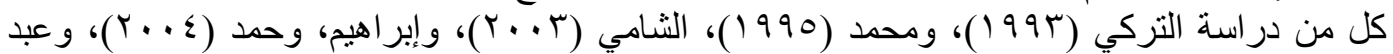

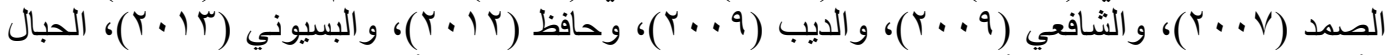

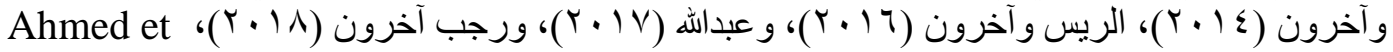

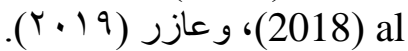

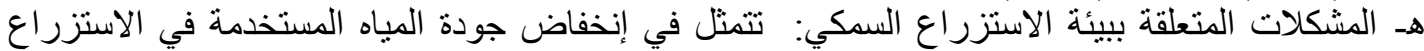

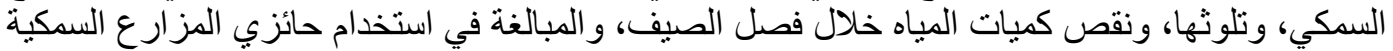

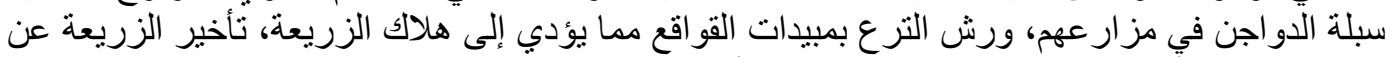

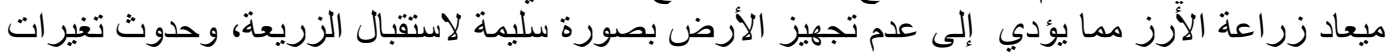

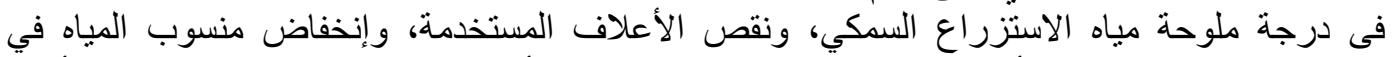

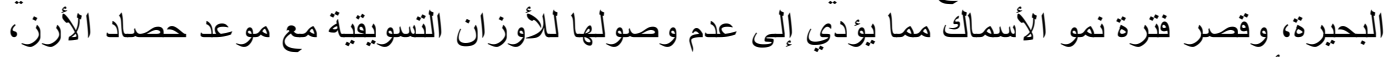

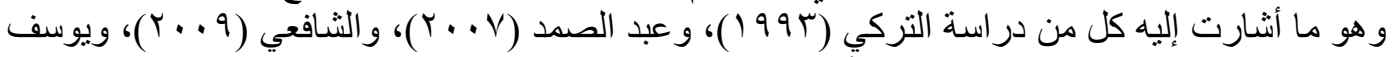

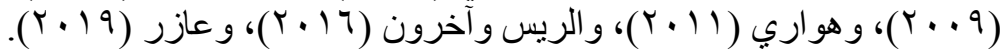

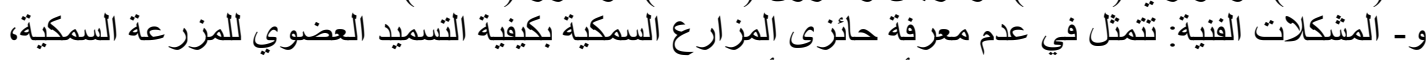

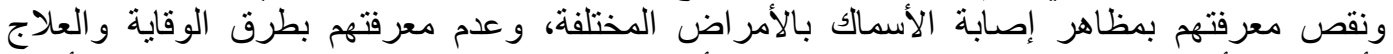

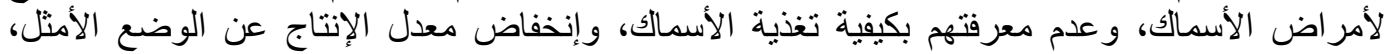

Fayoum J. Agric. Res. \& Dev., Vol. 34, No.2 July, 2020 


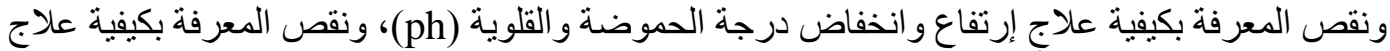

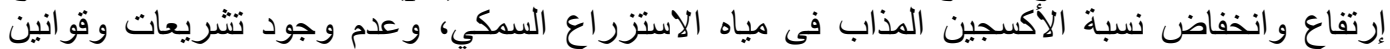

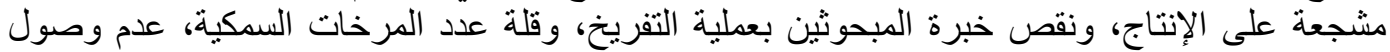

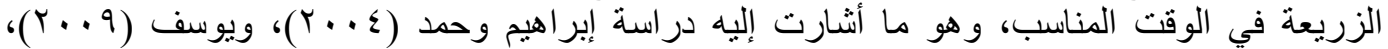

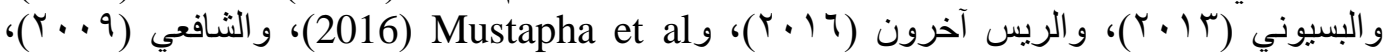

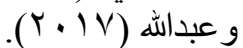

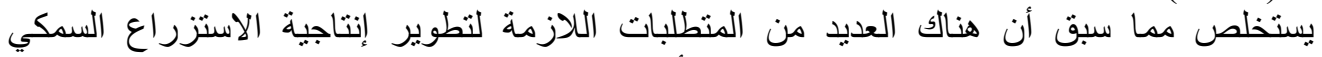

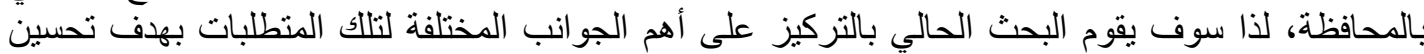
كفاءة المز ارع السمكية بالمحافظة.

وينضمن شُملة و عينة الداسة، أسلوب جمع البيانات، و التعاريف الإجر ائية والقياس الكمي لكتغيرات

$$
\text { الأسلوب البحثي }
$$
الدر اسة، و الأساليب الاحصائية المستخدمة، وذللك على النحو التالي: النيا:

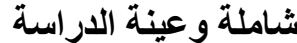

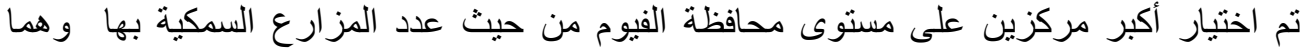

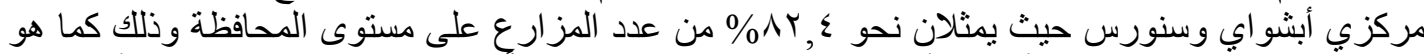

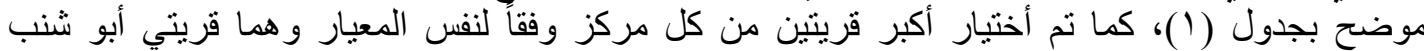

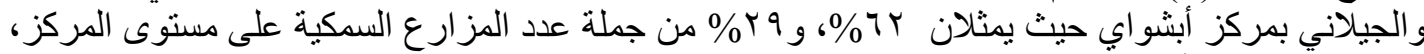

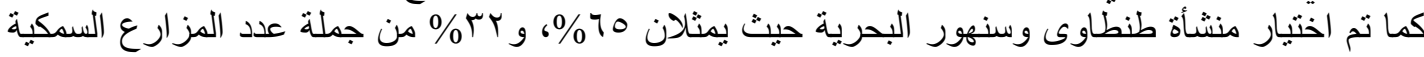

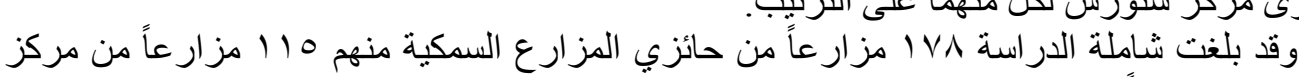

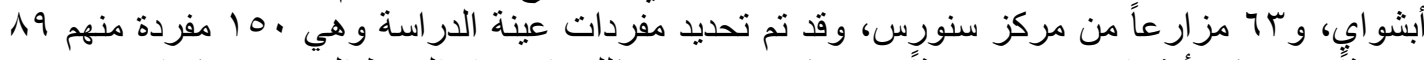

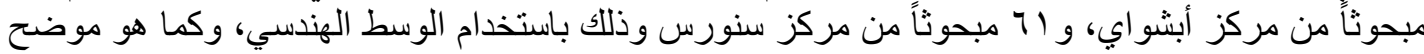

جلول (1) توزيع المزارع السمكية على مستوى مراكز محافظة الفيوم

\begin{tabular}{|c|c|c|c|c|}
\hline \multicolumn{2}{|c|}{ مساحة المزارع السمكية بالفدان } & \multicolumn{2}{|c|}{ المزارع السمكية } & \multirow[t]{2}{*}{ المركز } \\
\hline$\%$ & المساحة & $\%$ & عدد & \\
\hline $1 \wedge, \Gamma 7$ & 0.0 & or, Y & 110 & أبشواي \\
\hline $1 \varepsilon, 11$ & rAT & 49,17 & $\pi$ & سنورس \\
\hline $0 \cdot, \varepsilon$ & 1T人т & $V, \varepsilon$ & 17 & يوسف الصديق \\
\hline $1, V \leqslant$ & $\varepsilon \wedge$ & $\varepsilon, 7 T$ & 1 . & أطسا \\
\hline$r, \wedge V$ & 19 & $0, \cdot 9$ & 11 & طامية \\
\hline$\cdot, \wedge$ & Tr & $\cdot, \leqslant 7$ & 1 & الفيوم \\
\hline $11, \vee \wedge$ & $T r \varepsilon$ & & $\%$ Yo & مساحات زائدة \\
\hline & TVO. & & YIT & الإجمالي \\
\hline
\end{tabular}

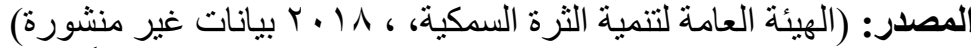

\begin{tabular}{|c|c|c|c|c|c|c|c|c|}
\hline \% & اللمركز الوسطى & علد مزارع & للقرية & اللقرسط & |المسانة & |المزارع| علد & القرية & المركز \\
\hline \multirow{3}{*}{$09, r$} & \multirow[b]{2}{*}{$r 19,1$} & 07 & $7, V$ & $1 r 0,1$ & TOV & VI & أبو شنب & \multirow[t]{2}{*}{ ا - أبشواى } \\
\hline & & r & $r \wedge, r$ & $\wedge \varepsilon$ & YI & Tr & الجيلانى & \\
\hline & & 19 & & $r 19,1$ & & $1 \cdot \varepsilon$ & & الإجمالي \\
\hline \multirow{3}{*}{$\varepsilon \cdot, \wedge$} & \multirow[b]{2}{*}{101} & $\sum 1$ & 77,0 & $1 \cdots, \varepsilon$ & $T \leqslant 7$ & §1 & منشأة طنطاوي & \multirow[t]{2}{*}{ ץ- سنورس } \\
\hline & & $r$. & $r r, 0$ & $0 ., 7$ & $1 \% 1$ & $r$. & سنهور البحرية & \\
\hline & $r v \cdot, 1$ & 71 & & 101 & & 71 & & 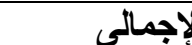 \\
\hline
\end{tabular}

Fayoum J. Agric. Res. \& Dev., Vol. 34, No.2 July, 2020 


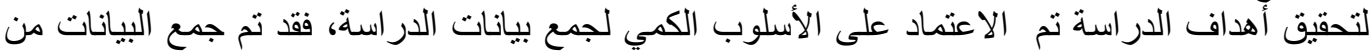

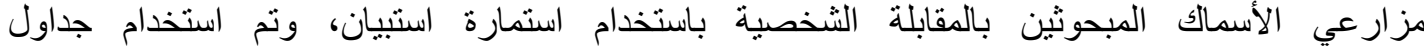

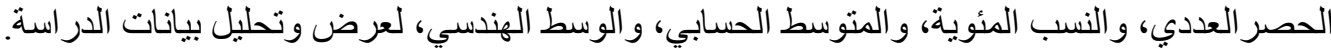

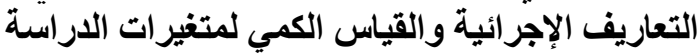

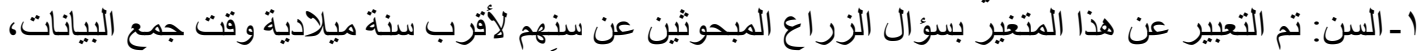

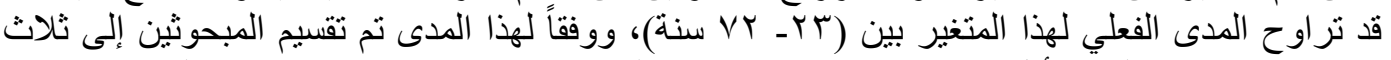

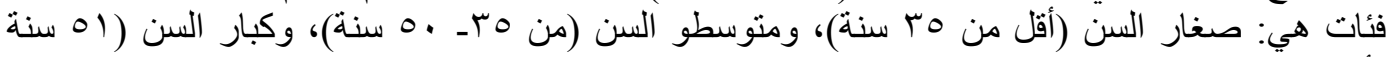

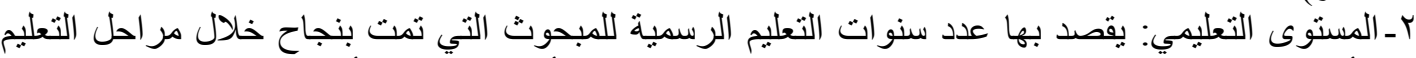

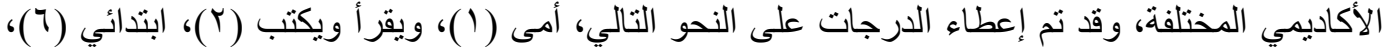

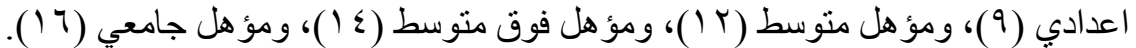

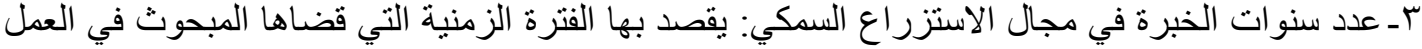

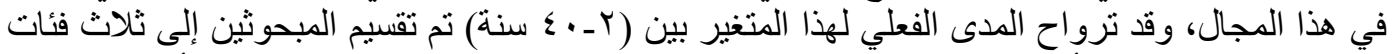

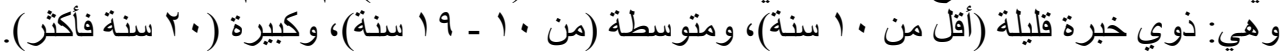

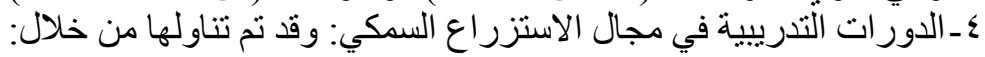

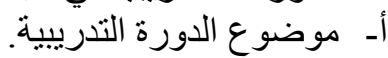

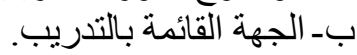

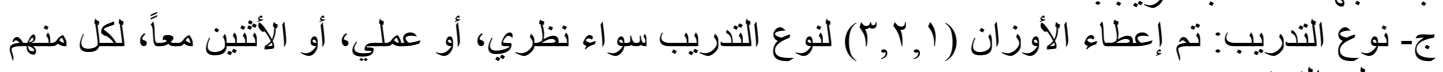
على الترتيب.

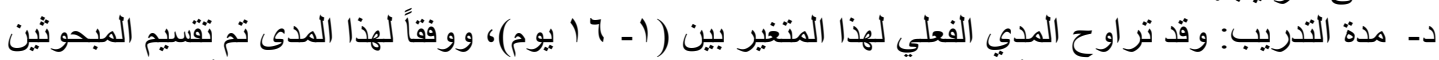

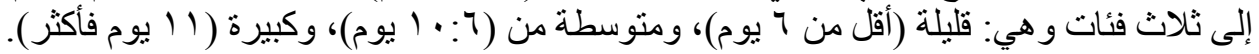

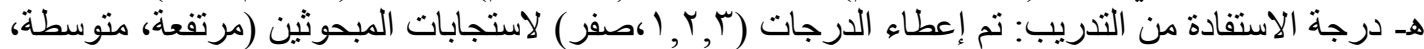

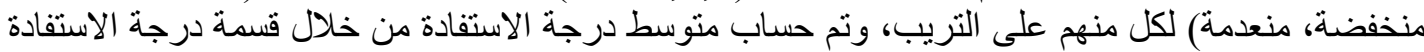

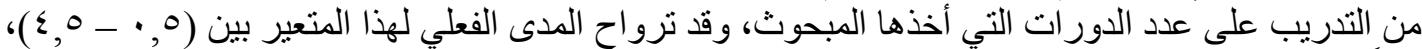

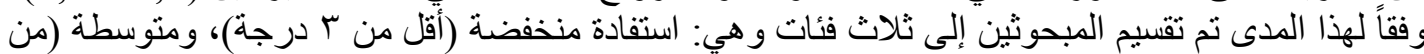

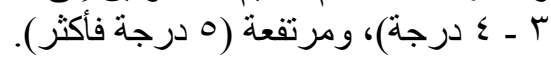

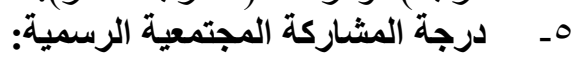

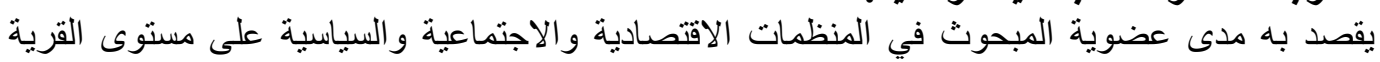

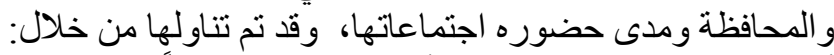

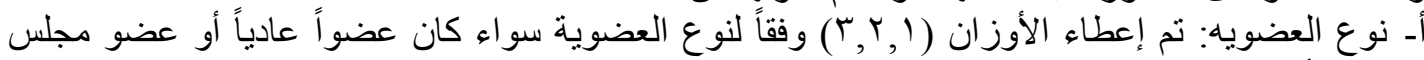

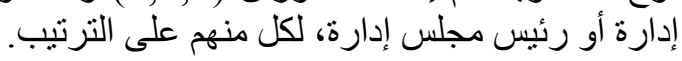

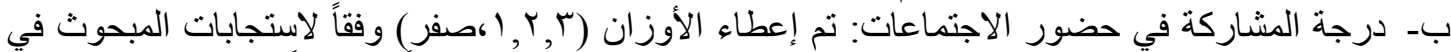

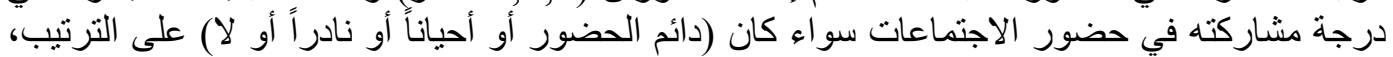

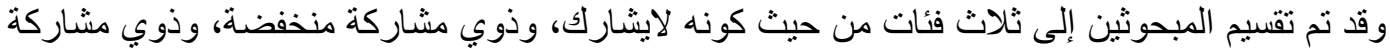

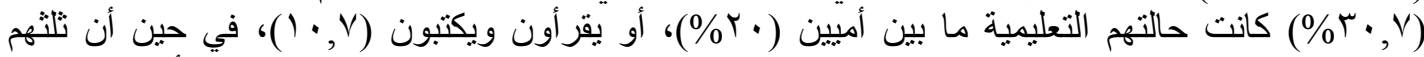

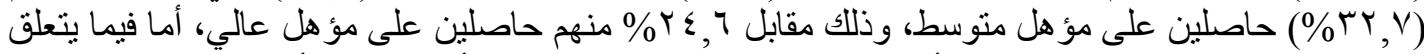

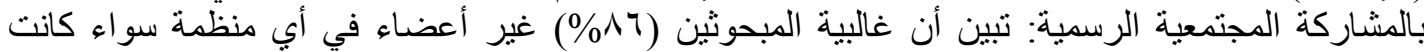

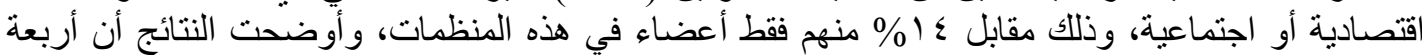

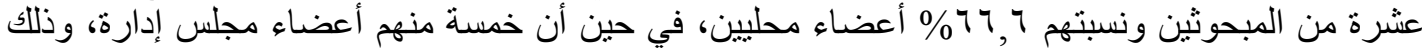

Fayoum J. Agric. Res. \& Dev., Vol. 34, No.2 July, 2020 


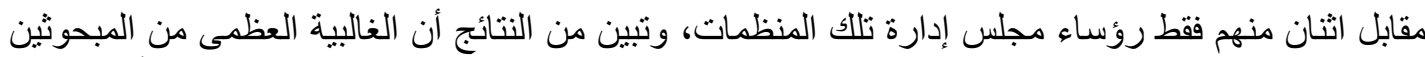

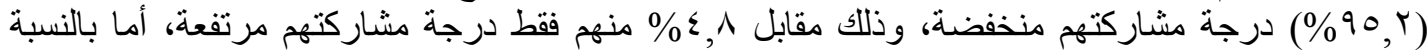

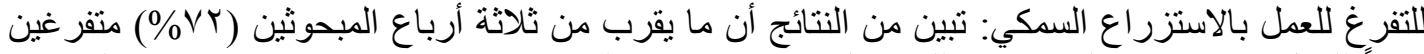

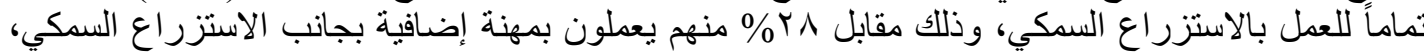

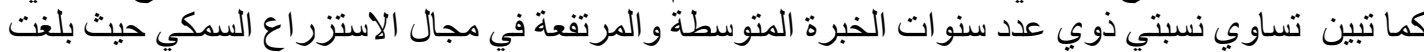

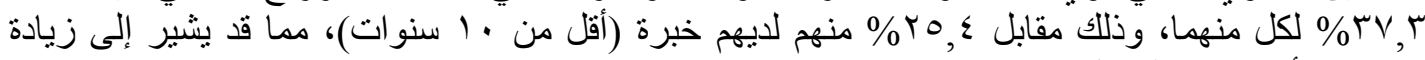
معرفتهم بأهمية هذا المجال و والاستثمار فيا.

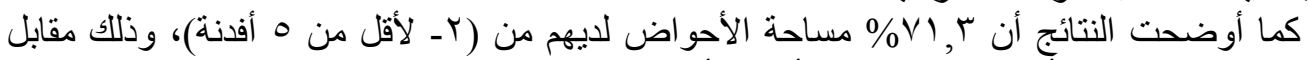

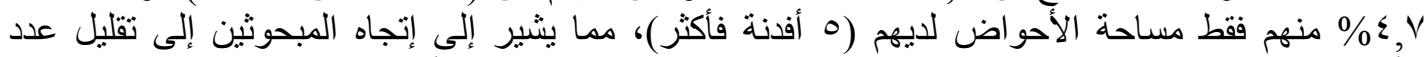

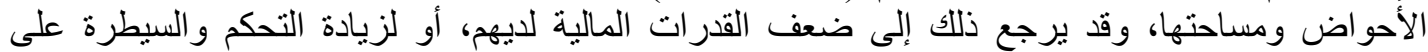

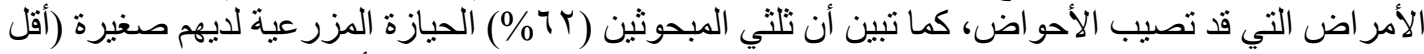

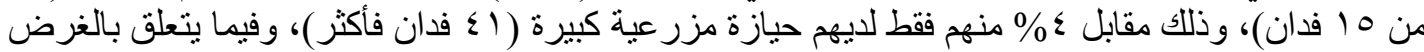

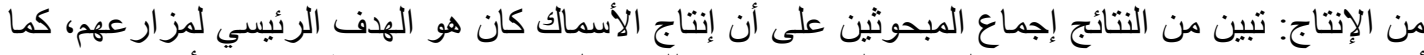

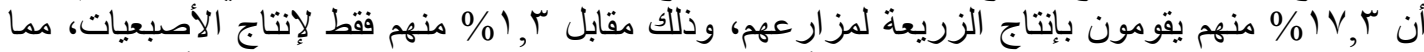

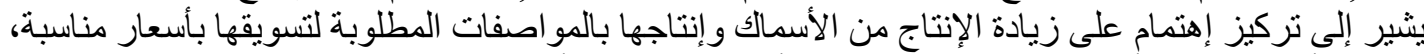

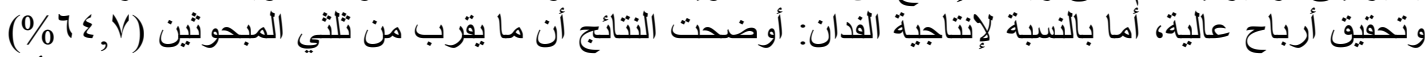

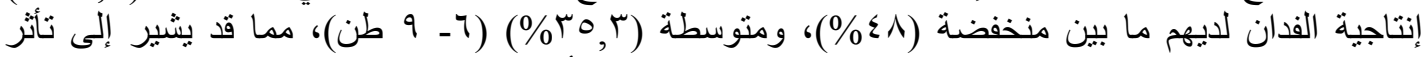

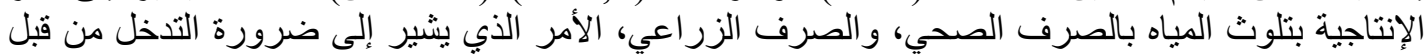

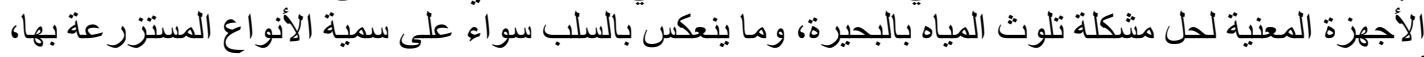
أو حتى على مستوى إنتاجيتها.

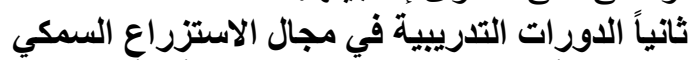

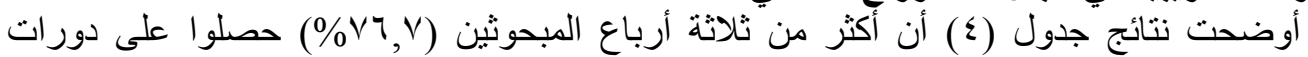

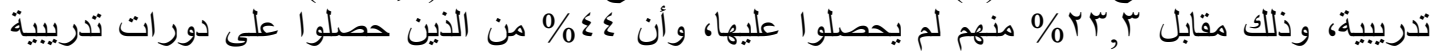

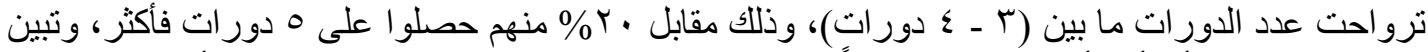

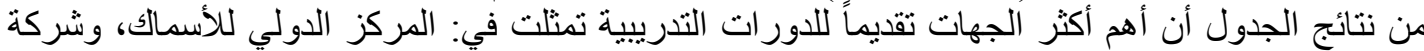

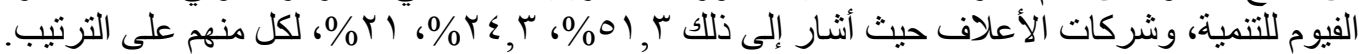

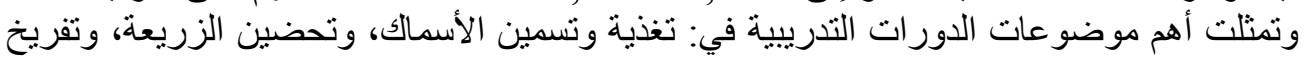

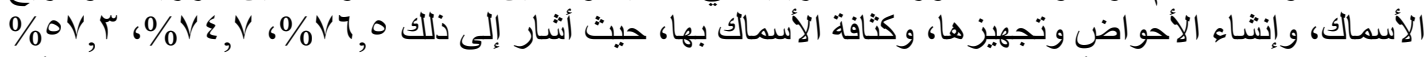

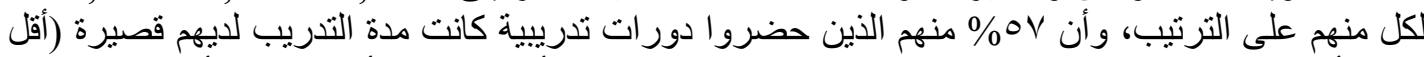

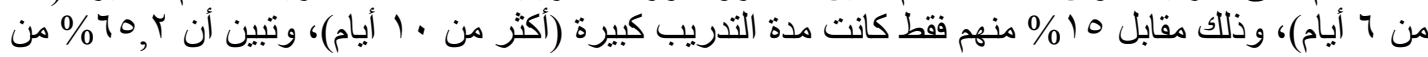

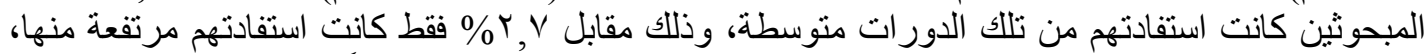

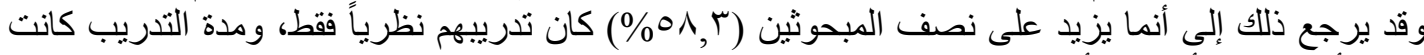

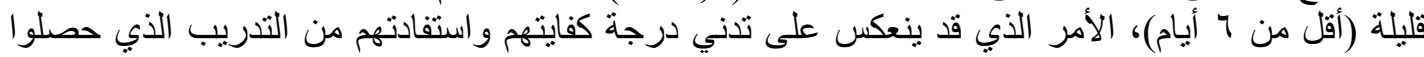

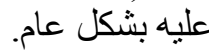

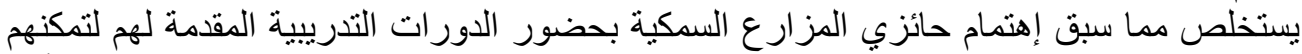

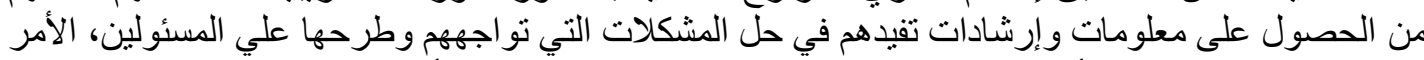

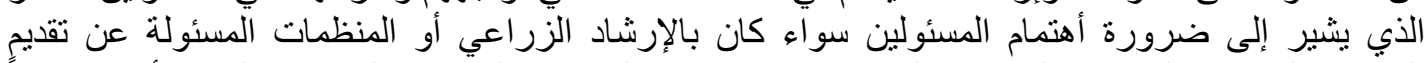

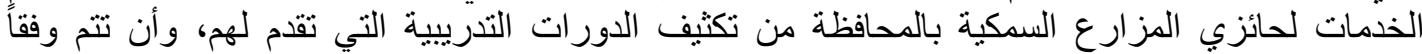

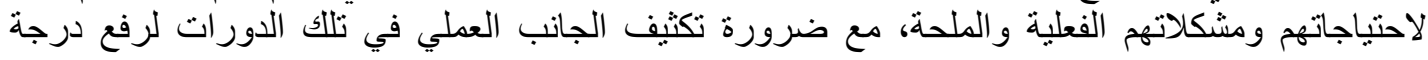


جدول (r) توزيع المبحوثين وفقاً لخصائصهم الثخصية والاقتصادية والاجتماعية

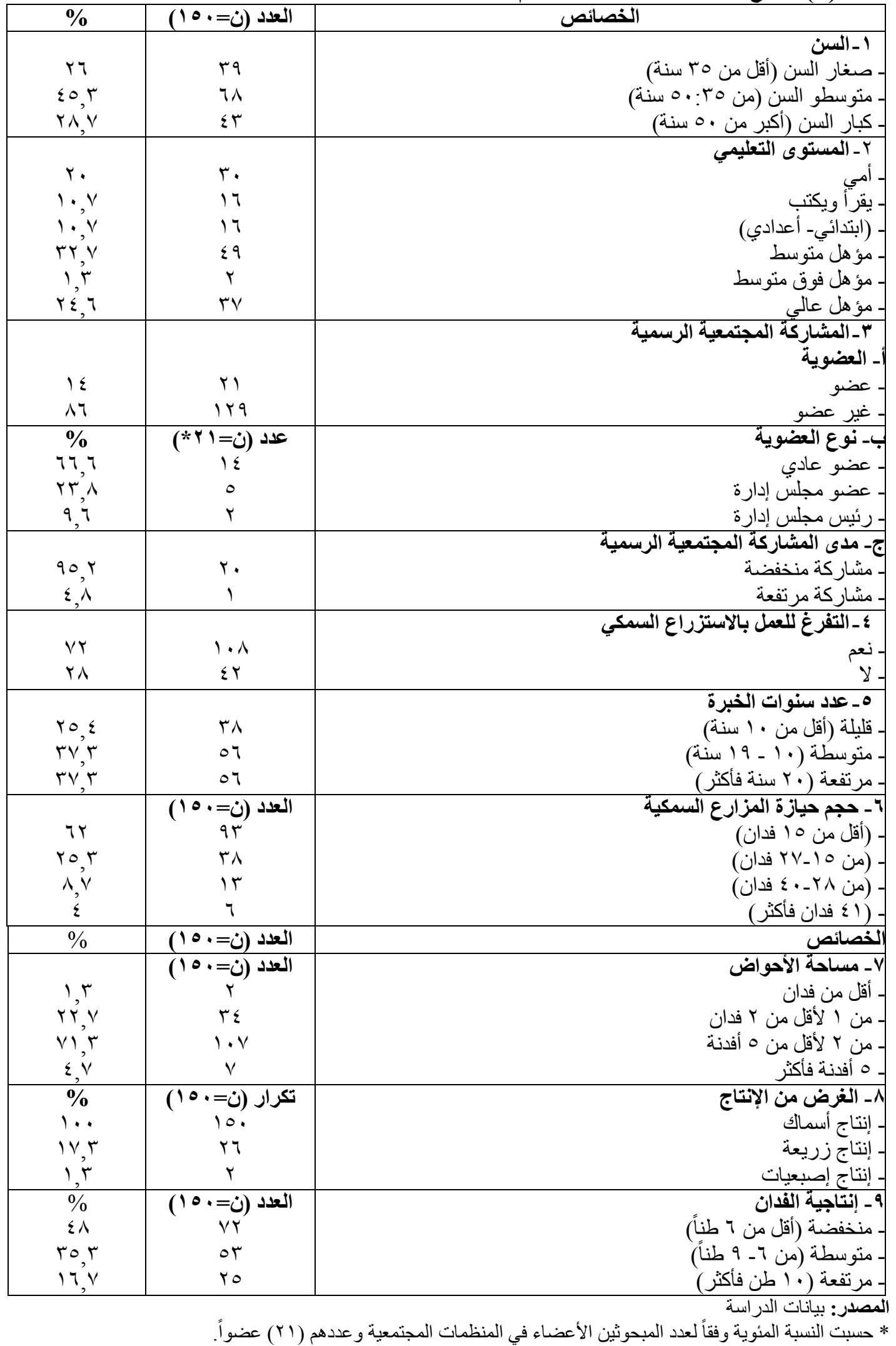

Fayoum J. Agric. Res. \& Dev., Vol. 34, No.2 July, 2020 
جدول ( ) ) توزيع المبحوثين وفقاً للاورات التدريبية في مجال الاستزراع السمكى

\begin{tabular}{|c|c|c|}
\hline$\%$ & عدد & الاورات المقدمة \\
\hline$\%$ & $(10 \cdot=\dot{0})$ & 1 - حضور التدريب \\
\hline$\vee \neg, V$ & 110 & ـ نع ن \\
\hline r & ro & $y-$ \\
\hline 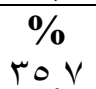 & العدد(ن= 1 (1) & ـ قلبلة عدد ألدورات من التدريبية \\
\hline ع & 01 & ـ متوسطة (من ץ - ع دورات) \\
\hline$r$. & r & ـ كبيرة (0 دور ات فأكثر ) \\
\hline$\%$ & تكرار(ن=0 1 (1*) & r-الجهة القائمة بالتّريب \\
\hline $01, r$ & 09 & ـ ـ المركز الدولي للأسماك. \\
\hline$r \leqslant, r$ & rᄉ & ـ شركة الفيوم للتنتمية. \\
\hline ri & $r \varepsilon$ & ـ شركات الأعلاف. \\
\hline $1 \cdot, \varepsilon$ & ir & ـ كليات الزر اعة والمر اكز البحثية. \\
\hline V & $\wedge$ & ـ خبر اء أجانب (تايلاند وفلسطين وبلجيكا). \\
\hline$\varepsilon, r$ & 0 & ـ الهيئة العامة لتنمية الثروة السمكية بالمحافظة. \\
\hline$\%$ & تكرار(ن=0 $11 *$ & ـ ـموضوع التدريب \\
\hline$v_{7}, 0$ & $\wedge \wedge$ & ـ تغذية وتسمين الأسماك. \\
\hline$V \leqslant, V$ & $\Lambda_{7}$ & ـ تحضين وتفريخ الزريعة و الأسماك. \\
\hline ov, & 77 & - إنشاء الأحو اض وتجهيز ها، وكثافة الأسماك بها \\
\hline$\leqslant 9,0$ & ov & ـ أنو اع الأمر اض وكيفية معالجتها. \\
\hline$\varepsilon \wedge, \uparrow$ & 07 & ـ أنو اع الأعلاف المستخدمة وجودتها. \\
\hline rv, & $\varepsilon r$ & ـ فرز الأسماك وتسويقها. \\
\hline$r$ r, & rv & ـ تحليل المياه وجودتها. \\
\hline $1 \leqslant, V$ & iv & ــ إدارة المزرعة السمكية. \\
\hline$\%$ & العدد(ن=0 ا | 1 (*) & هـمدة التدريب \\
\hline or & 77 & ـ صغيرة (أقل من 7 أيام) \\
\hline rA & r & ـ متوسطة (من 7- ـ ـ أيام) \\
\hline 10 & iv & ـ كبيرة ( ال يوم فأكثر) " \\
\hline$\%$ & العدد(ن=0 ا | 1 (*) & †ـ الاستفادة من التّريب \\
\hline$r$ r, & re & ـ منخفضة (أقل من ץ درجات) \\
\hline $70, r$ & vo & ـ منوسطة (من ץ - ـ درجات) \\
\hline$r, r$ & r & ـ مرتفعة (0 درجات فأكثر) \\
\hline
\end{tabular}

*حسبت النسبة المئوية وفقاً لعدد المبحوثين الذين حضروا دورات تدريبية في مجال الاستزراع السمكي وعددهم

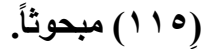
ثالثا: الخدمات الإرشادية الزراعية المقدمة في مجال الاستزراع السمكي

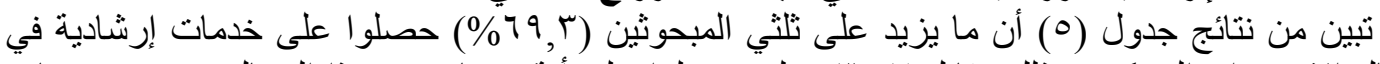

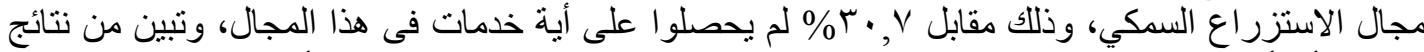

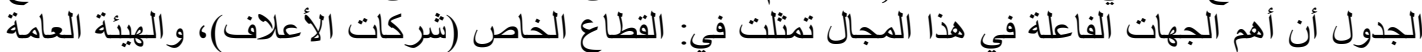

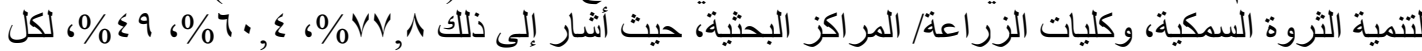

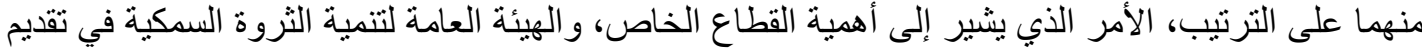

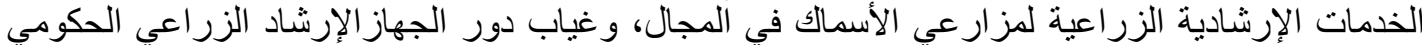

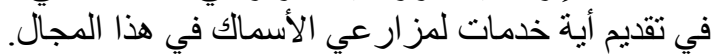

Fayoum J. Agric. Res. \& Dev., Vol. 34, No.2 July, 2020 
جدول (•) توزيع المبحوثين وفقاً لمدى تقديم الخدمات، وأهم الجهات الفاعلة في مجال الاستزراع السمكي

\begin{tabular}{|c|c|c|}
\hline$\%$ & عدد (ن= • & أ- مدى تقديم الخدمات \\
\hline $79, r$ & $1 \cdot \varepsilon$ & ـ نعم \\
\hline$r \cdot, v$ & $\leq 7$ & $\gamma-$ \\
\hline$\%$ & التكرار (ن=؛ • 1*) & بـ- الجهات \\
\hline$V V, V$ & 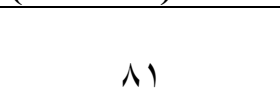 & أـ شركات الأعلاف \\
\hline$r \varepsilon$ & ro & بـ صبيدلية الأسماك \\
\hline $7 \cdot, \leqslant$ & זי & ـ الهيئة العامة لتنمية الثروة السمكية \\
\hline$\leqslant 9$ & 01 & ـ كليات الزر اعة/ المر اكز البحثية \\
\hline$r q, 1$ & M & ـ جمعية الاستزر اع السمكي \\
\hline
\end{tabular}

* حسبت النسبة المئوية وفقاً لعدد المبحوثين الذين حصلو ا على خدمات إرشادية و عددهم ( ـ ـ ( ) مبحوثاً.

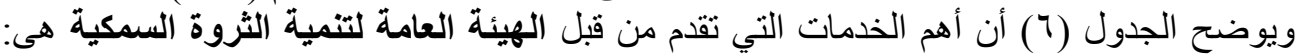

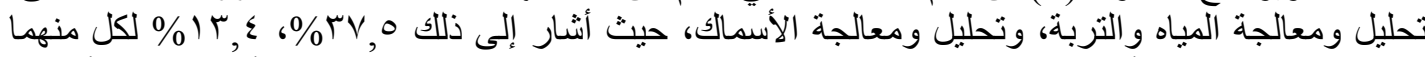

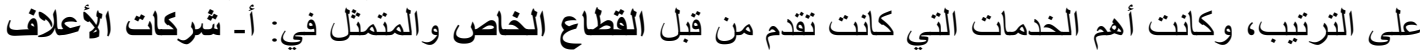

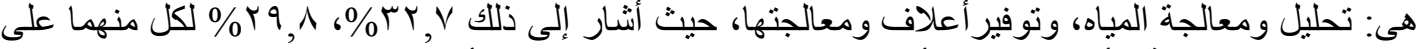

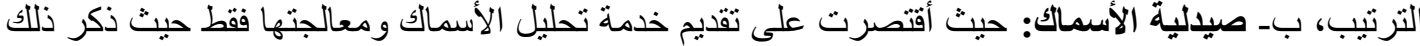

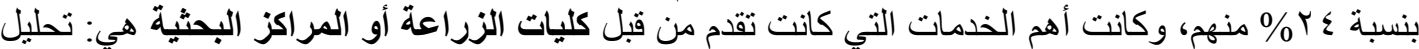

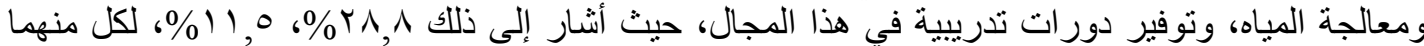

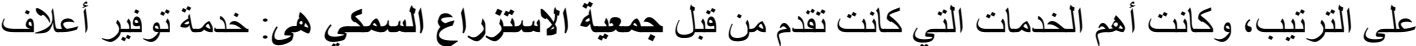

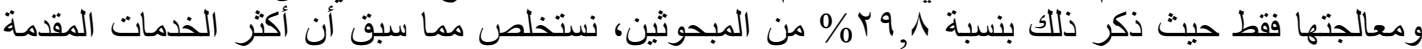

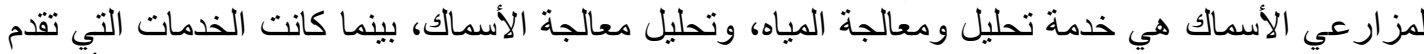

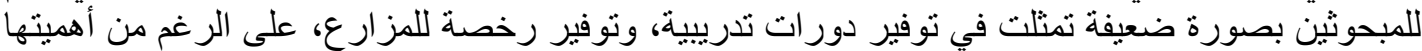

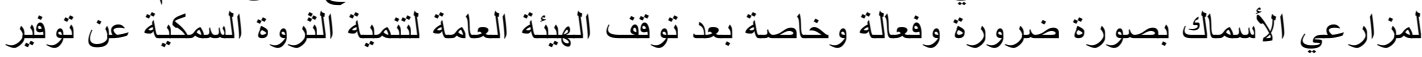

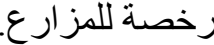
جدول (7) توزيع المبحوثين وفقاً لأهم الخدمات التي تقدمها الجهات الفاعلة في مجال الاستزراع السمكي

\begin{tabular}{|c|c|c|c|c|c|c|c|c|c|c|}
\hline \multirow{2}{*}{\multicolumn{2}{|c|}{ جمعية الأستزراع السمكي }} & \multirow{2}{*}{\multicolumn{2}{|c|}{ كليات الزراعة المرة }} & \multicolumn{4}{|c|}{ قطاع خاص } & \multirow{2}{*}{\multicolumn{2}{|c|}{ التميئة الثروة العامة }} & \multirow{3}{*}{ الخدمات } \\
\hline & & & & \multicolumn{2}{|c|}{ صبالأسماكّة } & \multicolumn{2}{|c|}{ شركات الأعلاف } & & & \\
\hline$\%$ & تكرار & $\%$ & تكرار & $\%$ & تكرار & $\%$ & تكرار & $\%$ & تكرار & \\
\hline- & - & $r \wedge, \wedge$ & $r$. & - & - & rY,V & $r \varepsilon$ & $r v, 0$ & $r q$ & - تحليل والتربة ومعالجة المياه \\
\hline - & - & $0, V$ & 7 & T乏 & ro & $10, r$ & 17 & $1 \Gamma, \varepsilon$ & $1 \leqslant$ & ـ تحليل ومعالجة الأسماك \\
\hline- & - & 11,0 & IT & - & - & - & - & $7, \mathrm{~V}$ & V & ـ توفير دور ات تدرييية \\
\hline$r q, \wedge$ & M & $r, \Lambda$ & $r$ & - & - & $r q, 1$ & T & - & - & توفير أعلاف ومعالجتها \\
\hline- & - & - & - & - & - & - & - & $r, \Lambda$ & $r$ & ـ توفير رخصة للمز ارع \\
\hline
\end{tabular}

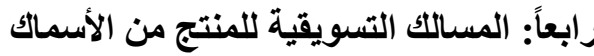

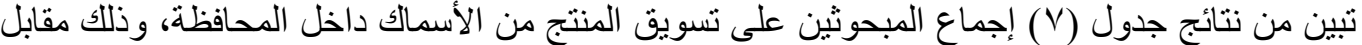

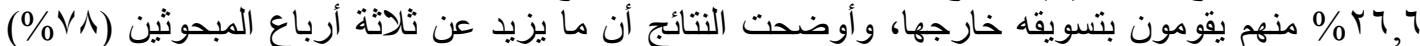

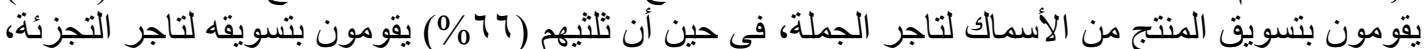

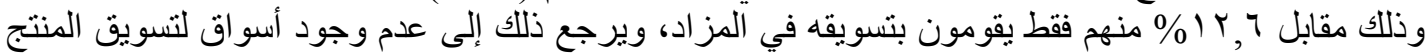

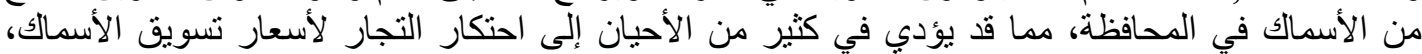

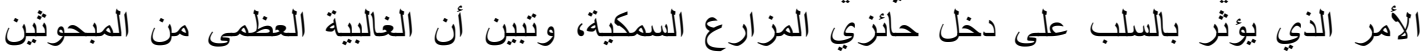

Fayoum J. Agric. Res. \& Dev., Vol. 34, No.2 July, 2020 


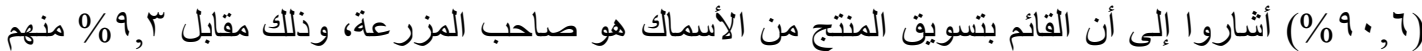

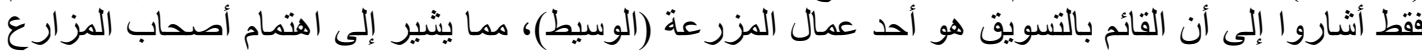

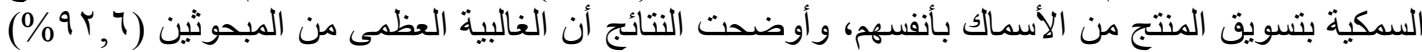

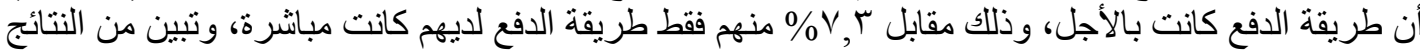
إجماع المبحوثين على عدم ثبات أسعار الأسماك.

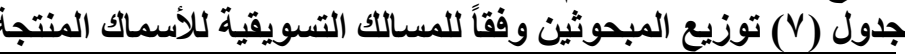

\begin{tabular}{|c|c|c|}
\hline$\%$ & تكرار & المسالك التسويقية \\
\hline$\%$ & تكرار (ن) • 10 (10) & ــ دـ نظلم المحافظيقة \\
\hline r & $\varepsilon$ & ـ خار ج المحافظة \\
\hline$\%$ & تكرار (ن=•• & بـ نوعية التسويق \\
\hline VA & $11 \mathrm{~V}$ & ــ تاحر الَحملة \\
\hline 77 & 99 & ـ تاجر التجزئة \\
\hline $1 Y, 7$ & 19 & ـ ـ المزاد . \\
\hline$\%$ & 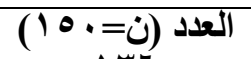 & ج- القائم بالتسويثي \\
\hline $9, \frac{1}{q}$ & $1 \leqslant$ & ـ أحد عمال المزر رعة (اله سبط) \\
\hline$\%$ & اللعدد (ن=، & دـ طريقة الدفع \\
\hline 94.7 & 1\%q & ـ ـ بالأجل \\
\hline$v, r$ & 11 & ـ مباشر \\
\hline$\%$ & العدد (ن=•ا) & هـ مدى ثُبات الأسعار \\
\hline . & 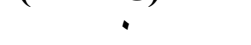 & ـ ثابتة \\
\hline $1 \ldots$ & 10. & ـ ـ غير ثابتة \\
\hline
\end{tabular}

خامساً: المشكلات التي تواجه المبحوثين في مجال الاستزراع السمكي ومقترحاتهم لعلها

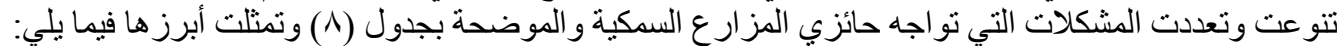

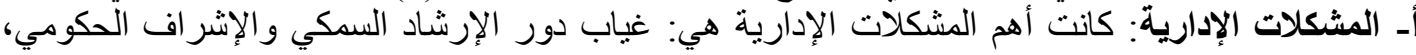

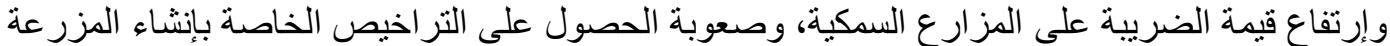

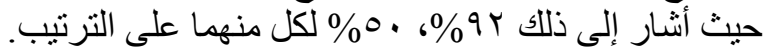
ب- ب المشكلات الاقتصادية والتمويلية: أجمع المبحوثين على التى أن أهم المشكلات الاقتصادية والتمويلية

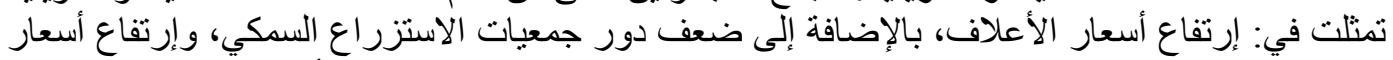

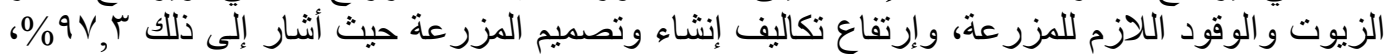

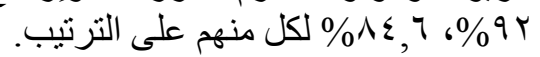

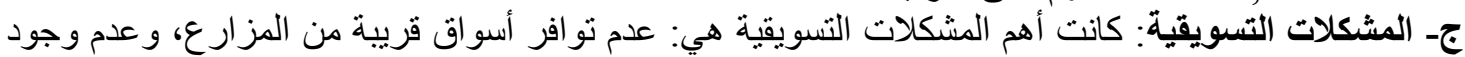

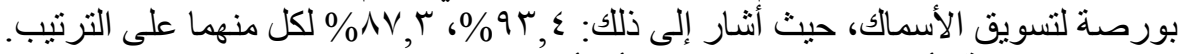

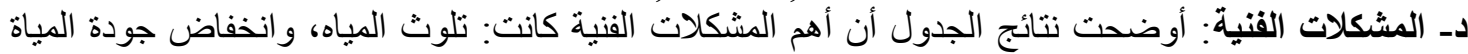

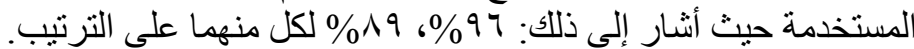

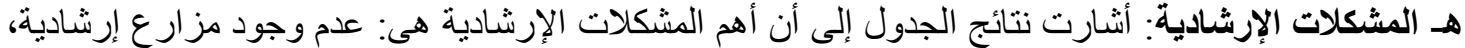

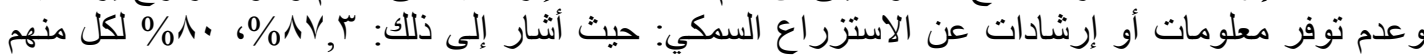
على الترتيب. و - مشكلات أخرى : أوضحت نتائج الجدول أن أهم المشكلات الأخرى تمثلت في: عدم وجود اتحادات لحائزي

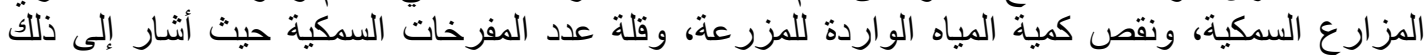

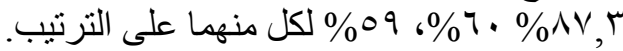

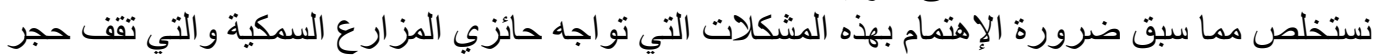

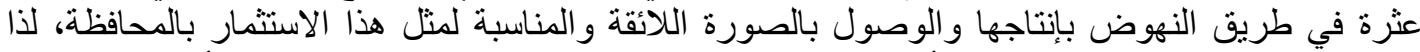

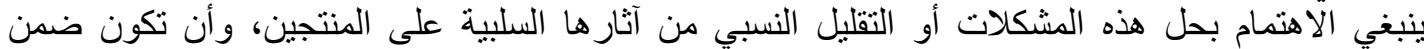
أولويات الجهات التنفيذية ومنها الجهاز الإرشادي و الأجهزة المعنية بتقديم الخدمات الإرشادية الزية الزراعية.

Fayoum J. Agric. Res. \& Dev., Vol. 34, No.2 July, 2020 
جلول (^) توزيع المبحوثين وفقاً للمشكلات التي تواجههم في مجال الاستزراع السمكي

\begin{tabular}{|c|c|c|}
\hline$\%$ & التكرار (ن=• 10) & المشكلات \\
\hline & & 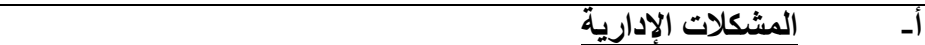 \\
\hline $9 \vee, r$ & $1 \leqslant 7$ & غياب دور الإرشاد السمكي و الإشر اف الحكومى. \\
\hline 94 & $1 \mathrm{k}$ & إرتفاع قيمة الضريبة على المز أرع السمكية. \\
\hline 0 . & vo & ـاخيص الخاصة بإنشاء المزرعة. \\
\hline $19, \Gamma$ & rq & عدم وجود قاعدة بيانات عن المزرعة. \\
\hline & & ب- بـ المشكلات الإقتصادية والتمويلية \\
\hline & & 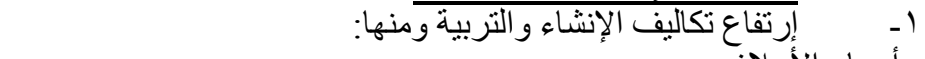 \\
\hline $1 \cdots$ & 10. & ـ ـ أسعار الاعلاف. ـ \\
\hline$\Lambda \leq, 7$ & IrV & ـ ـ أسعار الزيوت و الوقود اللازمة للمزرعة. \\
\hline ז'r & 90 & ـ ـ أسعار الكهرباء. \\
\hline 11,7 & rی & 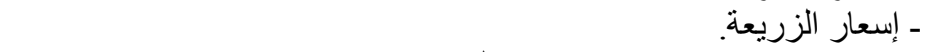 \\
\hline 94 & $1 \mathrm{k}$ & ז- ضعف دور جمعيات الاستزر اع السمكي \\
\hline $\mathrm{VA}$ & $11 \mathrm{~V}$ & r- إرتفاع تكاليف إنشاء وتصميم الَّزرعة. \\
\hline$\uparrow \Lambda, 7$ & $1 \cdot \pi$ & ـ ـ إرتفاع تكاليف إيجار أو شراء المزرعة. \\
\hline $7 \leq, 7$ & 9v & هـ إرتفاع القيمة الإيجارية لآلات الحفرو الردم. \\
\hline$\mu, r$ & $\varepsilon v$ & ا ـ صعوبة الحصول على قروض، و إرتفاع أسعار الفائدة. \\
\hline$r, T$ & Tะ & Vـ عدم قدرة حائزي المز ارع السمكية على التمويل الذاتي. \\
\hline & & ج- المشكلات التسويقية \\
\hline $9 ז, r$ & $1 \varepsilon$. & ا - - عدم تو افر أسو اق قريبة من المز ارع. \\
\hline$\Delta v, r$ & $1 \pi 1$ & عدم وجود بورصة لتسويق الأسماك. \\
\hline$V V, r$ & 117 & عدم استقرار أسعار بيع الأسماك. \\
\hline ז & 90 & احتكار بعض التجار للإنتاج السمكي. \\
\hline 07 & $\Lambda \varepsilon$ & 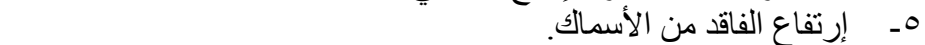 \\
\hline$\varepsilon V$ & $v$. & إنخفاض أسعار بيع وتسويق الأسماك. \\
\hline זr & $\leqslant 9$ & قلة المعلومات المتوفرة عن تسويق الأسماك. \\
\hline $11, r$ & IV & صعوبة نقل الأسماك إلى أماكن التسويق و إرتفاع تكاليف النقل. \\
\hline & & دـ المشكلات الفنية: \\
\hline 97 & $1 \leq \varepsilon$ & 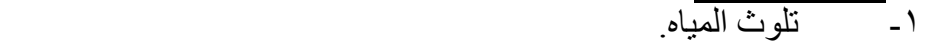 \\
\hline 19 & זrו & إنخفاض جودة المياه المستخدمة. \\
\hline $\mathrm{v}$ & 1. & 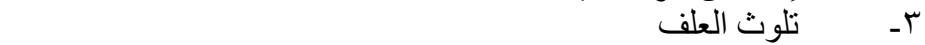 \\
\hline & & هـ المشكلات الإرشاديةٌ \\
\hline$\Lambda$. & Kr. & 1 - عدم وجود مز ارع إرشادية. \\
\hline$v \vee, r$ & 117 & r بـ عدم توفر معلومات أو إرشادات عن الاستزراع السمكي. \\
\hline$T V, r$ & $1 \cdot 1$ & ץ- عدم إمداد المز ار عين بالمطبو عات الإرشادية. \\
\hline$\varepsilon v$ & v. & ـ ــ نقص الكو ادر الفنية المدربة في المجال. \\
\hline ra & $\sum r$ & 0ـ ـقص خبرة المز ارعين بعطية التفريخ. \\
\hline 14 & 19 & آ- عدم توفير فرص للالتحاق بالدور ات التدرييية. \\
\hline $1 \pi, r$ & r. & V- عدم وجود وسيلة لإنتقال المرشد لزيادة المز ارع. \\
\hline$\Lambda$ & ir & 1ــ عدم الإعلان عن مو اعبد الندو ات الإرشادية. \\
\hline & & و- مشكلات أخرى . . ب. \\
\hline$\Lambda V, r$ & $1 \pi$ & 1- ـ عدم وجود اتحادات لحائزي المز ارع السمكية. \\
\hline 7. & $9 \cdot$ & بـ ــ نقص كمية المياه الواردة للمزرعة. \\
\hline 09 & $\Lambda \Lambda$ & بـــ قلة عدد المفرخات السمكية. \\
\hline ז & 0. & ــ - إنخفاض منسوب المياه في البحبرة. \\
\hline$r$. & $\leqslant 0$ & 0ـ ضعف البنية الأساسية و الخدمات العامة. \\
\hline 11 & rV & ד- سوء حالة الطرق بين المزارع ومر اكز تجميع الزريعة ونفوق الكثير منها. \\
\hline $11, r$ & iv & 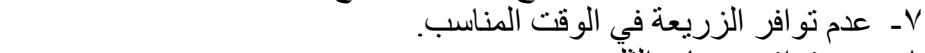 \\
\hline 9 & 14 & 1 -ـ عدم تو افر مصانع الثلج. \\
\hline
\end{tabular}

Fayoum J. Agric. Res. \& Dev., Vol. 34, No.2 July, 2020 
وتمثلت أهم مقترحات المبحوثين للتظلب على المعوقات التي تو اجههم في مجال الاستزر اع السمكي السمي فيما يلي:

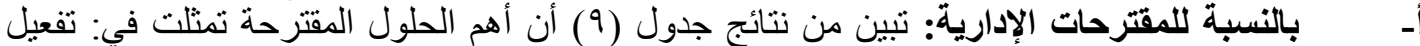

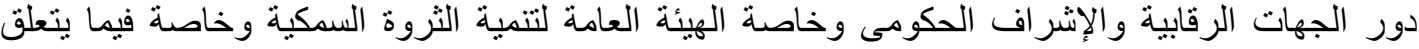

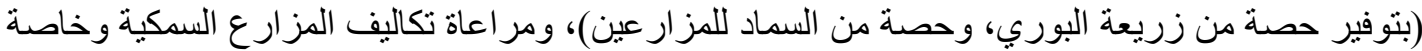

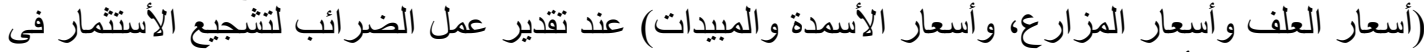

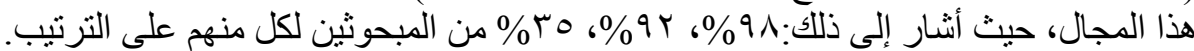

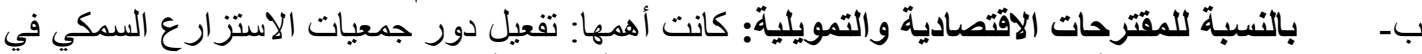

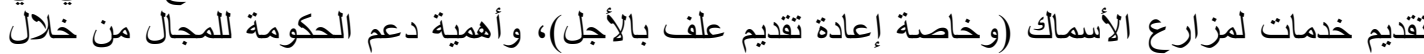

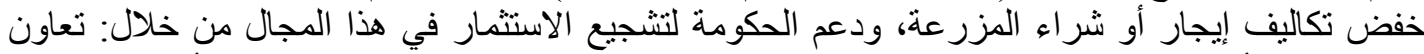

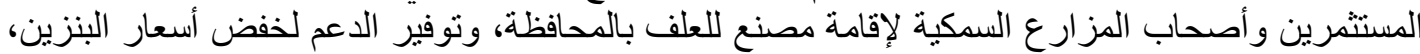

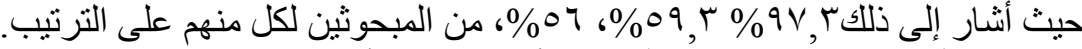

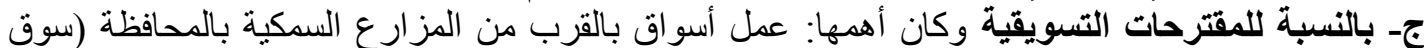

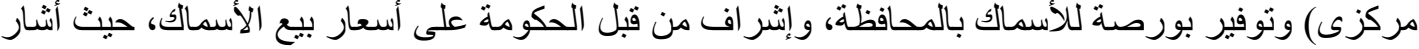

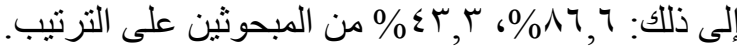

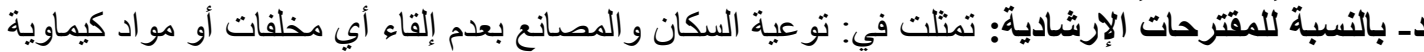

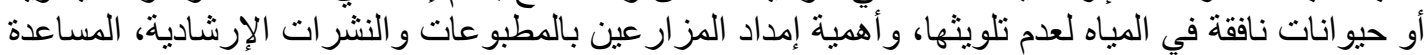

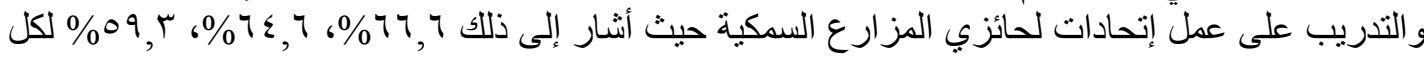

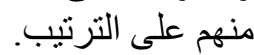

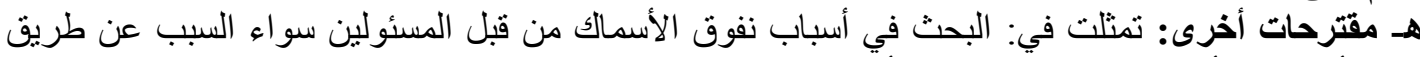

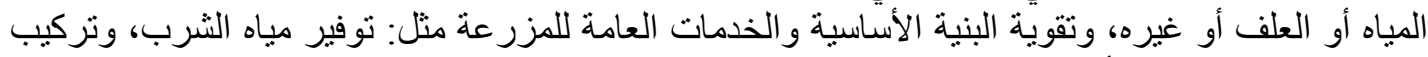

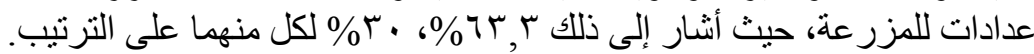

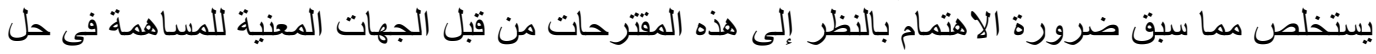

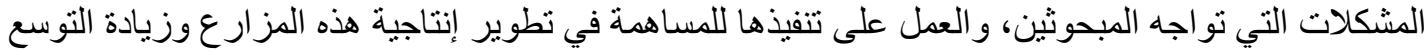

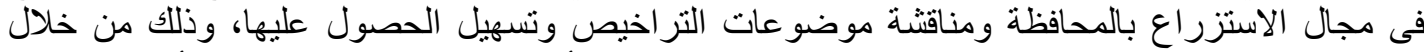

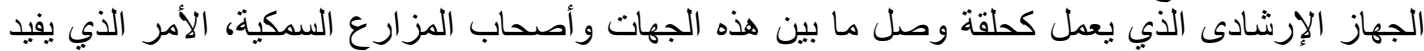

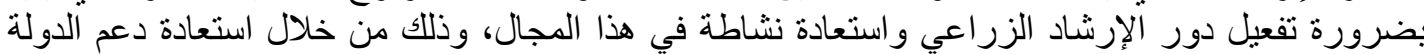

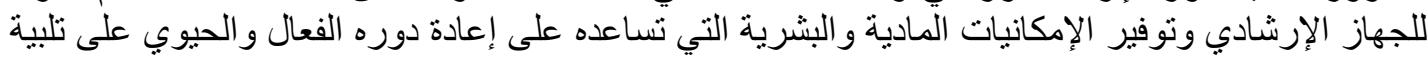

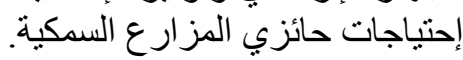




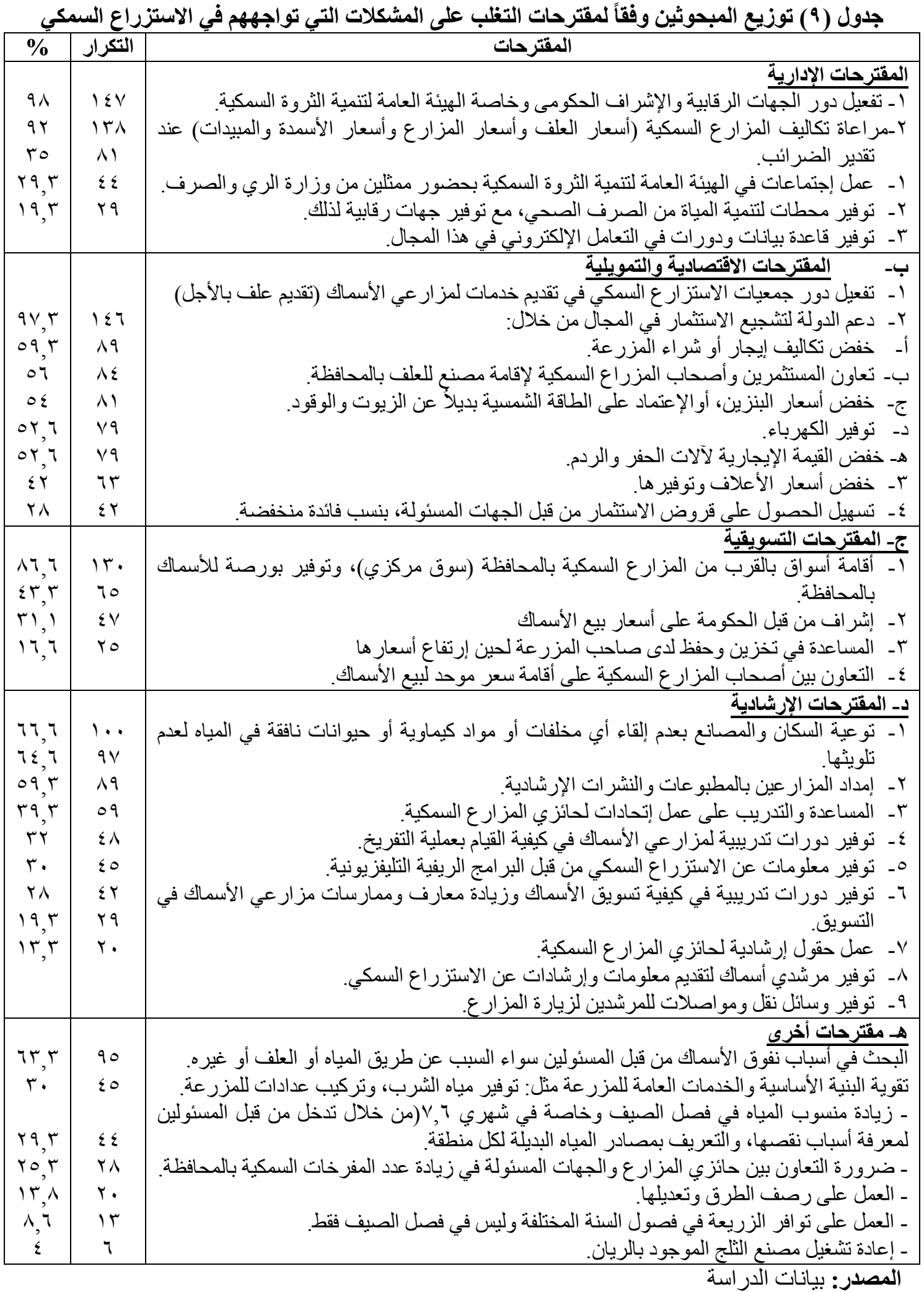

Fayoum J. Agric. Res. \& Dev., Vol. 34, No.2 July, 2020 
في ضو وع ما أسفرت عنه نتائج الدر اسة أمكن استخلاص التوصيات التوريات التالية:

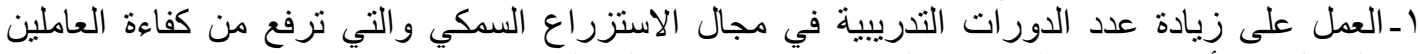

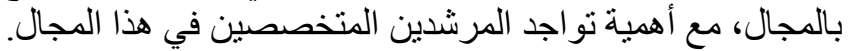

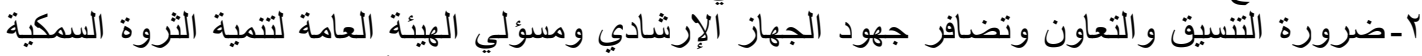

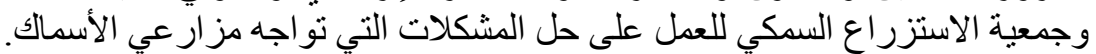

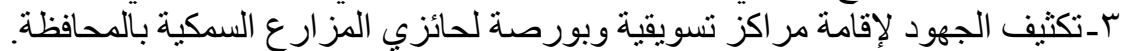

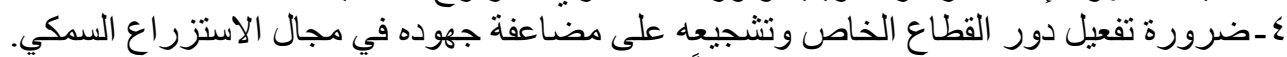

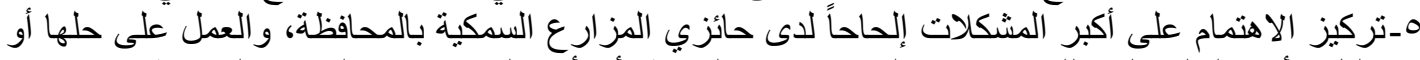

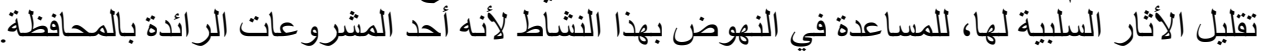

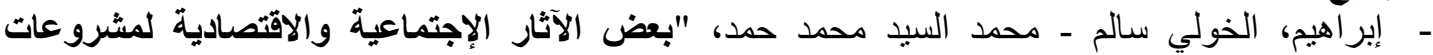

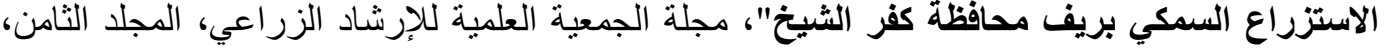

ـ ـ الأصقة، ناصر بن عبداله ـ السيد محمد إبراهيم يونس، "الاستزراع السمكي تقنية وإدارة"، النشر العلمي

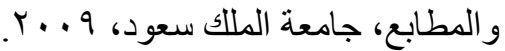
- البسيوني، سحر محمود محمد، "دور الإرشاد الزراعي في تنمية استزراع الأسماك في حقول الأرز في

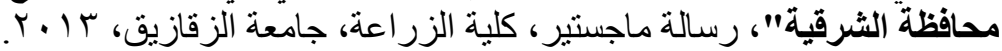

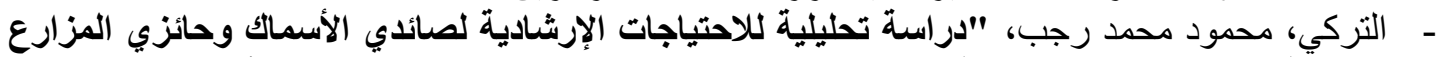

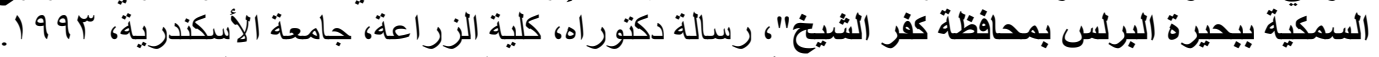

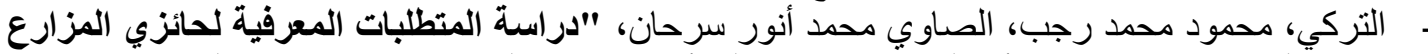

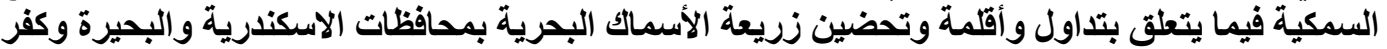

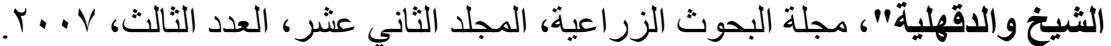

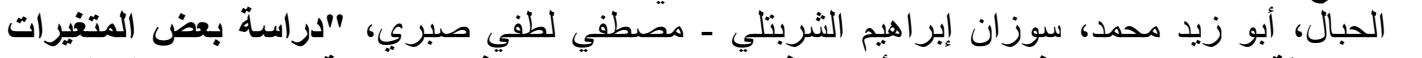

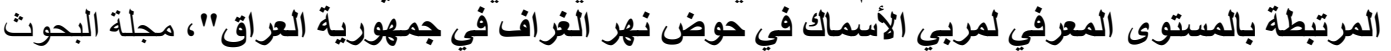

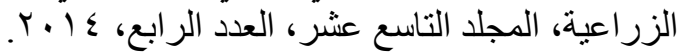

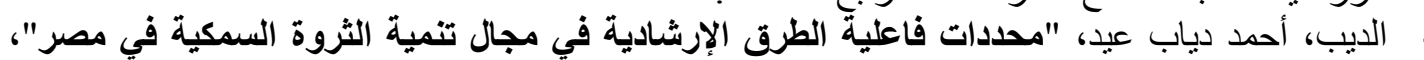

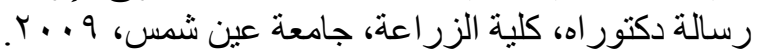

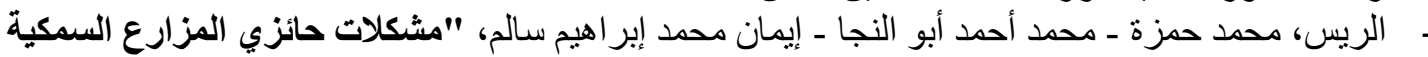

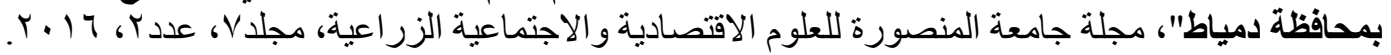

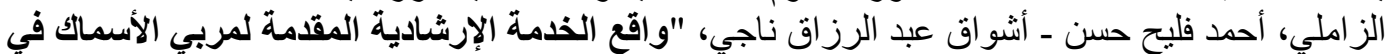

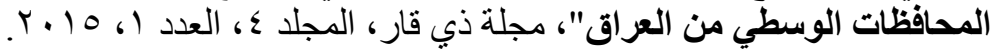

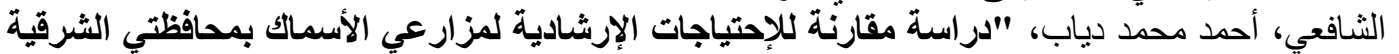

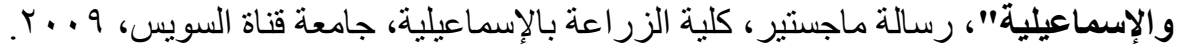

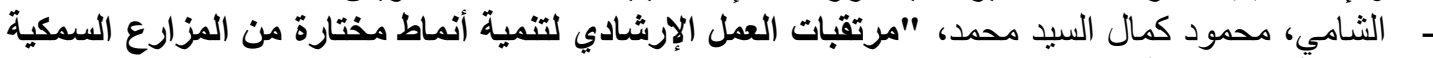

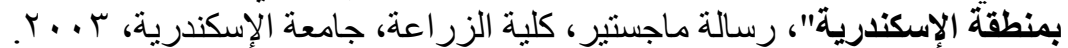

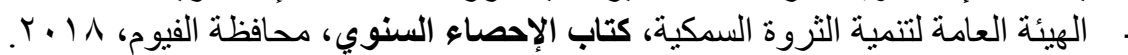

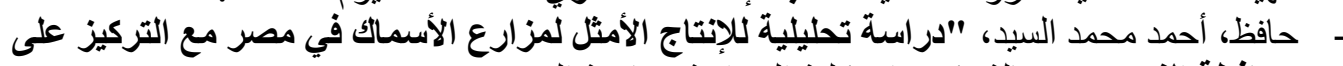

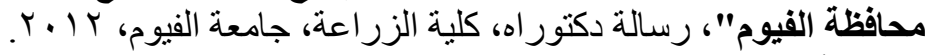

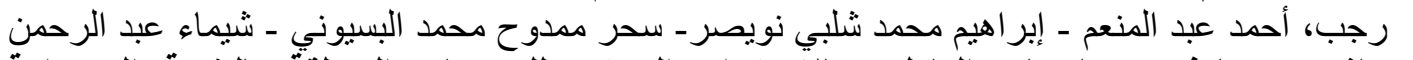

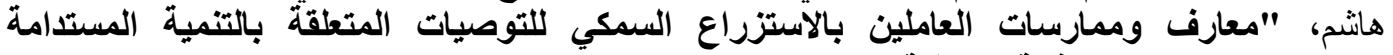

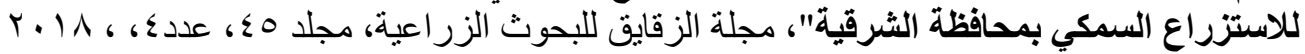

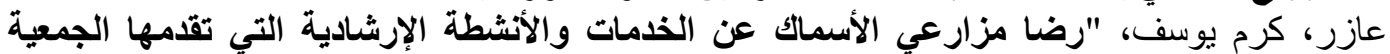

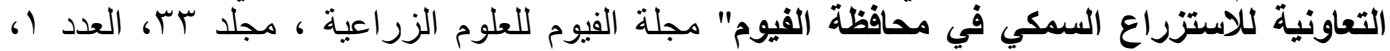


عامر، عادل أحمد ثروت، "مقدمة في الإنتاج السمكي"، مركز الترجمة والتأليف والنشر، كلية العلوم

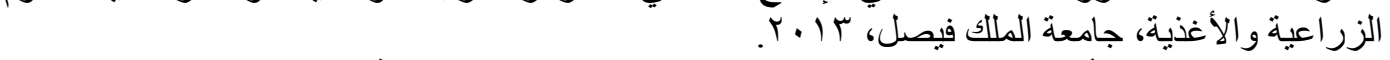

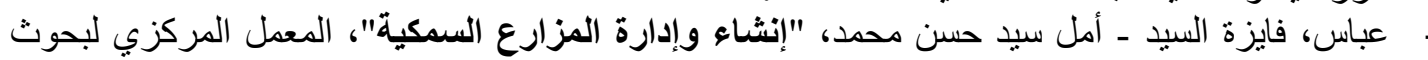

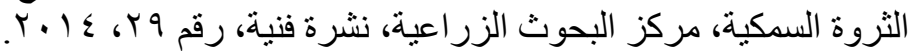

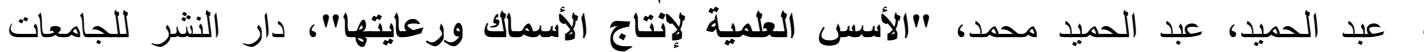

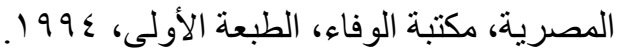

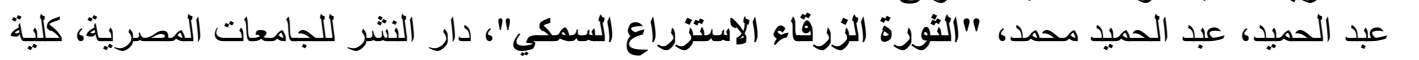

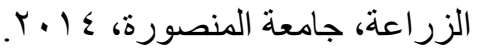

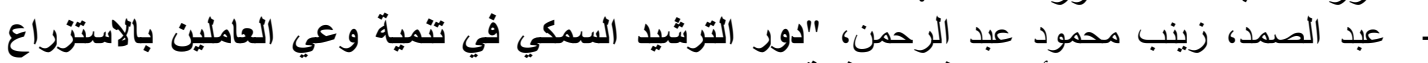

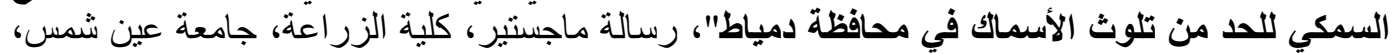

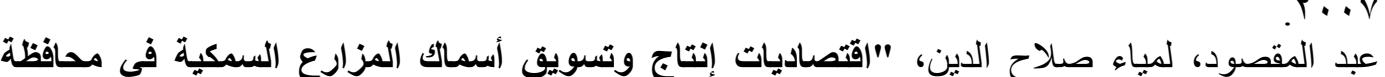

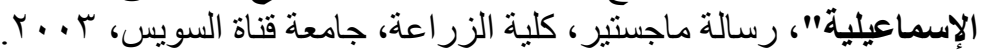

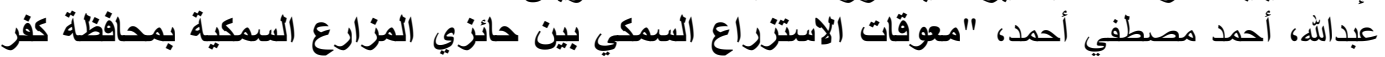

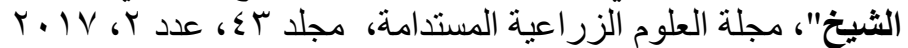

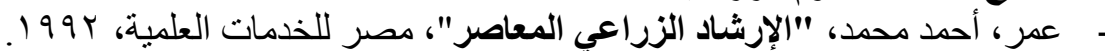

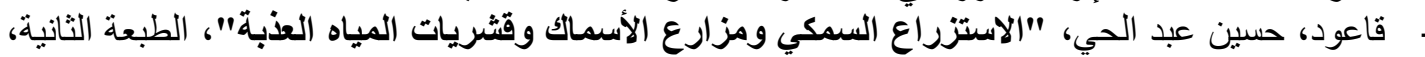

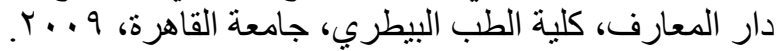

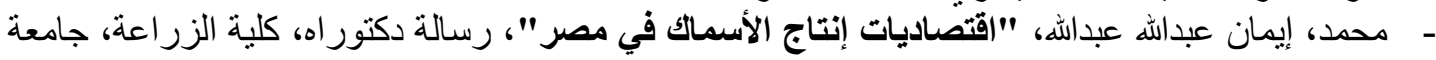

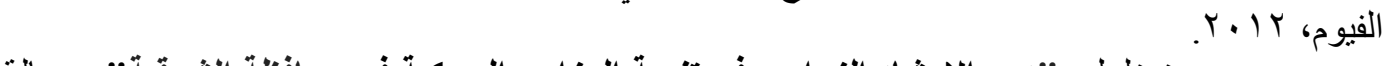

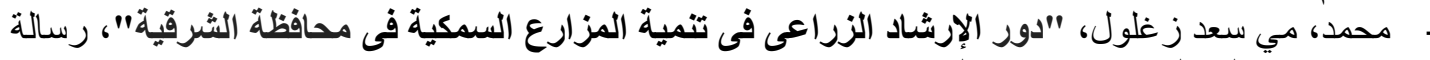
ماجستير، كلية الزر اعة، جامعة الزقازية الإنيق، هو اري، هناء محمد، "دافعية الإنجاز لإى حائزية الزئية المزارع السمكية في محافظة الفيوم"، مجلة الجمعية

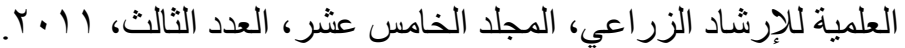

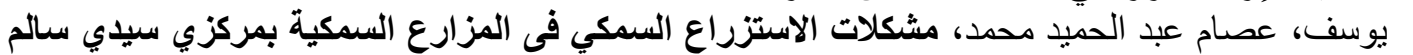

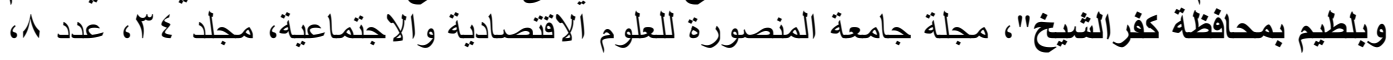
r... 9

- Ahmed, Zakir, Asaduzzamn Sarker, Zulifkar Rahman, Baokun Lei, Zannatun Nahar Mukta, "Fisheries extension in Bangladesh and local extension angent for fisheries: A micro level assessment of farmers' Attitude", International Journal of Fisheries and Aquatic Studies, 6(4): 92103,2018 .

- Hashmi, Sakib - Safiul Islam Afrad, " Adoption of Modern Aquaculture Technologies by the Fish Farmers in Bogra District of Bangladesh", International Journal of Agriculture Innovations and Research Volume 3, Issue 2, 2014.

- Mustapha, S.B, Mustapha, A.A., Reuben, A.B, Obtta, N. C., Alkalia, "Assessment of Extension Service Delivery on Fish Farming in Maiduguri Metropolis, Borno State, Nigeria", Vol. 3, No. 9, 2016. 


\title{
REQUIREMENTS OF FISH FARM OWNERS IN FAYOUM
} GOVERNORATE

\begin{abstract}
The study aimed to: identify the socio-economics characteristics of the respondents, Recognize the delivered training courses in the field of aquaculture, Identify the most important services provided by the actors involved in aquaculture, identify the best ways that respondents prefer for fish marketing, and identify the most important problems facing respondents in this field and their suggestions to solve it, study was conducted in fayoum governorate where the two largest districts according to the number of fish farms were selected, (Ibshway and Senouras), Two villages were selected from each district according to the same criteria, as the sample reached to 150 respondents Aquestionnaire by interview.

The most important findings could be summarized as follows: $76.7 \%$ of the respondents attend courses combared with $23.3 \%$ did not attend training courses, and all respondents reported that the most important marketing channels were inside Fayoum governorate, and $78 \%$ of them indicated marketing fish product to wholesaler, and $90.6 \%$ indicated that the marketer is farm owner also (92.9\%) of them pointed that the payment way is in credit finally, all respondents indicated that price of fish not fixed. $69.3 \%$ of the respondents indicated that they received extension services in this field, and the most important actors were: private sector(Fodder companies), and the General authority for fish resources development (GAFRD) as mention by $77.8 \%, 60.5 \%$ respectively.

Finding also revealed that the most important problems facing respondent were: the most important problems facing respondent were: high price of feed (100\%), absence of both fish extension role and governmental supervision (97.3\%), water pollution(96\%), absence of unions for fish farms owners (87.3\%), and absence of extension farms $(80 \%)$.
\end{abstract}

Fayoum J. Agric. Res. \& Dev., Vol. 34, No.2 July, 2020 